\title{
CLOSENESS IS NOT ACCESSIBILITY: ISOLATION AND DEPOPULATED RURAL AREAS IN THE PROXIMITY OF METROPOLITAN URBAN AREAS, A CASE-STUDY IN INLAND SPAIN
}

\author{
Martínez Sánchez-Mateos, H. S., Ruiz Pulpón, A. R. ${ }^{1}$
}

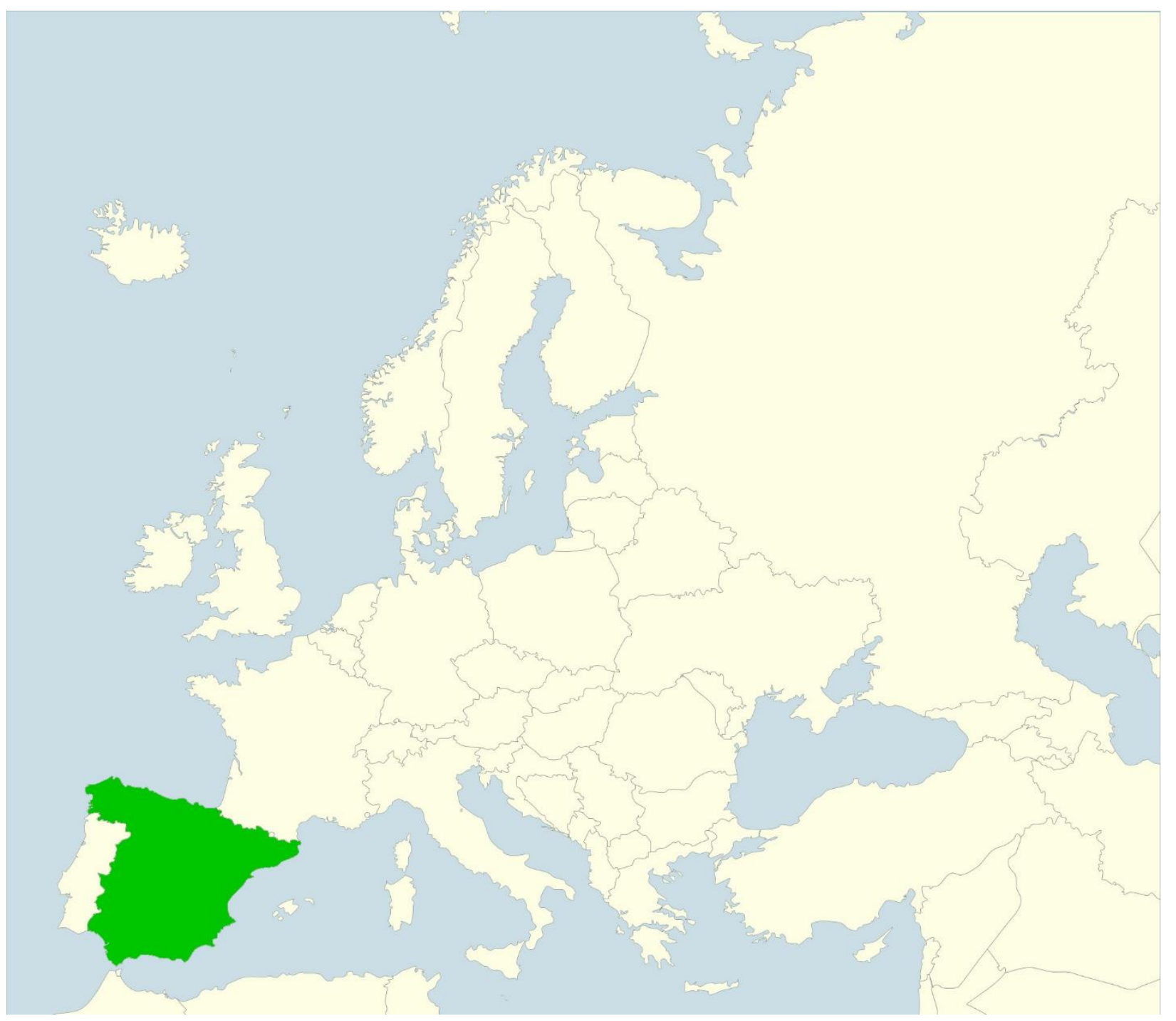

${ }^{1}$ Martínez Sánchez-Mateos, Héctor S., ORCID: 0000-0002-3613-9958, e-mail: HectorS.Martinez@uclm.es, Ruiz Pulpón, Ángel Raúl, Dpt. Geography and Land Planning, University of Castilla-La Mancha, ORCID: 0000-0002-35977394, e-mail AngelRaul.Ruiz@uclm.es 


\begin{abstract}
The increase of accessibility is one of the most important strategies to achieve territorial cohesion and slow down depopulation processes in rural areas. Accessibility is a wide concept with a range of interpretations. When it comes to rural areas, usual accessibility measures introducing proximity and ease of physical connection could lead to misinterpretations and a lack of knowledge for rural areas. This study proposes an accessibility analysis based on connection and function of one of the most depopulated territories in inland Spain: the province of Guadalajara (NUTS-3) which constitutes an interesting case-study because its proximity to the Spanish capital city (Madrid) and the integration of part of the province on its dynamics and economic processes. Results show different rural accessibility levels useful for public policies and decision making on infrastructures. In addition, the accessibility model suggested can be applied in other depopulated rural areas of Europe.
\end{abstract}

Key words: Accessibility, Depopulated rural areas, proximity, Guadalajara province

Resumen: La mejora de la accesibilidad es una de las estrategias más importantes para lograr la cohesión territorial y ralentizar los procesos de despoblación en las zonas rurales. La accesibilidad es un concepto amplio con una amplia gama de interpretaciones. Cuando se trata de zonas rurales, las medidas habituales de accesibilidad que introducen proximidad y facilidad de conexión física pueden conducir a interpretaciones erróneas que no siempre responden con la realidad. Este estudio propone un análisis de accesibilidad basado en la conexión y función de uno de los territorios más despoblados del interior de España: la provincia de Guadalajara (NUTS-3), que constituye un interesante caso de estudio por su proximidad a la capital española (Madrid) y la integración de parte de la provincia en sus dinámicas y procesos económicos. Los resultados muestran diferentes niveles de accesibilidad rural que pueden ser útiles para el diseño de políticas públicas y la toma de decisiones sobre infraestructuras. Además, el modelo de accesibilidad sugerido puede aplicarse en otras zonas rurales despobladas de Europa.

Palabras clave: Accesibilidad, Áreas rurales despobladas, proximidad, provincia de Guadalajara

\title{
Highlights:
}

- Rural municipalities in the proximity of urban centres do not assure either good accessibility or demographic growth.

- The processes of exogenous industrial development lead to spatial unbalances conditioning the accessibility.

- The location of facilities for health care and education have a string influence in the level of rural accessibility.

\section{Introduction}

The relationship between the deterioration of rural areas and access to essential services has been studied for quite some time (Gutiérrez, 1991), with the concept of a connection to the urban system at the heart of the debate (Farrington and Farrington, 2005). Access to services is analysed based on general considerations that consider how services and facilities are distributed around the area and the way in which they are accessed (Salze et al., 2011). This article proposes that there is a relationship between depopulation and accessibility, with the latter to be understood not only as a measure of proximity to goods and services but also as a factor reflecting the level of cohesion within a territory. The working hypothesis of this paper is that closeness (proximity) does not reflect the potential for effective access to goods and services, since areas with good territorial positioning, and short distances, can have accessibility problems. These areas are 
essentially rural, so that, by nature, they are isolated from more dynamic areas and related to the concept of peripherality (Heffner and Latocha, 2020; Kühn, 2015). With this approach, the main objective addressed in the article is to test the relationship between demographic dynamics and accessibility, demonstrating that closeness is not sufficient to achieve effective accessibility and, therefore, territorial cohesion.

Demographic aspects play a key role in the current Territorial Cohesion Policy (EU, 2013). Demographic behaviour, and in particular, natural and spatial dynamics, influence the ability of territories to interrelate with each other, to respond to possible territorial imbalances mainly due to the concentration of population in urban areas, and to become resilient and competitive in the current process of globalisation. According to the European Territorial Agenda 2020, the main demographic challenges that the territorial cohesion process must confront immediately are an ageing population and rural depopulation, since these phenomena affect, among others, the design of essential public services, housing policies and the organisation of the labour market (EU, 2011: 6). An ageing population can be judged to be an irreversible, global phenomenon resulting from the generalisation of the welfare state but, when applied to rural areas, it represents the most revealing consequence of the strong processes of migration between the countryside and the city that have occurred in recent decades. On the other hand, rural depopulation is one of the main factors in the current social and spatial change in rural areas, along with others, such as counter-urbanisation and transnational migration (ESPON, 2011; Pinilla et al., 2008; Collantes et al., 2013; Woods, 2016; Reynaud and Miccoli, 2018; Labianca and Navarro, 2019). Even though the loss of population affects all kinds of territories, it has been particularly intense in areas with a low population density, putting the principles of territorial cohesion at risk (EU, 2016; Delgado, 2019).

According to the European Union, sparsely populated areas are those with fewer than 8 inhab. $/ \mathrm{km}^{2}$ in NUTS-2 territories and fewer than 12.5 inhab. $/ \mathrm{km}^{2}$ in NUTS-3 territories (EU, 2016). This indicator generally fails to consider the complexity of sparsely populated rural areas, which corresponds to different geographical realities, depending on the specific territorial characteristics of each European country. In addition, there are other qualitative factors that would favour a better understanding of these types of spaces (Nordregio, 2012: 13). Nevertheless, these areas do have characteristics in common, such as a low population density and a fragile economy, which are related, in turn, to serious difficulties with territorial integration and isolation (Delgado, 2019: 343) and have led to the migration of the young and adult population. The resulting shrinkage of the labour force has severely limited the possibilities for local economic development and increased the degree of population ageing. Poor economic dynamism, compounded in recent years by the financial crisis and austerity measures (Bock, 2016: 552), has led to other risks to territorial cohesion, such as increasing social exclusion and an inability to improve the transport network and accessibility. In the opinion of the ESPON European Observatory, the links between rural and urban areas should be organised according to principles of territorial connection, by limiting the dependence on urban areas and the marginalisation of areas in rural decline (ESPON, 2011); but urban-rural interrelations are very limited in sparsely populated areas, and much more dynamic in rural areas close to large cities that have a good transport infrastructure. Therefore, areas that are difficult to access or with tenuous flows into and out of urban areas experience a "vicious circle" of rural decline (ESPON, 2011; EU, 2019). This view is echoed by the Territorial Agenda 2020, which insists on improving accessibility and the role of small and medium-sized towns as connectors with the rural environment (EU, 2011).

Marginalization and backwardness of rural areas has also been analysed under the centreperiphery theories, that interpret this situation under three different perspectives (Heffner and Lactocha, 2020: 125): a) a geographical matter related to position; b) an economic issue linked to the role of spaces in the productive system; and c) a social problem connected with the power system and decision-making processes, where peripheries experiment a lack of selfindependence. The first is the traditional positional perspective, where location and distance determines centres and peripheries. In our debate, closeness stands for proximity and locational perspective, which potentially would mean good accessibility; but peripheralization is multiscale and process centred (Kühn, 2015: 374). We shall explore the relationship between 
sociodemographic trends and accessibility to test the idea that being close to a centre is not enough to invert negative dynamics.

A situation exists, therefore, in which it is necessary to make decisions at an overarching territorial level to retain the population by implementing specific regulatory frameworks that address the problem of rural depopulation. Although the LEADER Community Initiative and successive Territorial Agendas start from in-depth territorial diagnoses in order to promote territorial development formulas that will help to maintain the population level, by themselves, they are not measures specifically dedicated to reversing the depopulation of rural areas (EU, 2016; Labianca and Navarro, 2019: 227) because they lack specific policies for preventing depopulation at the local or community level (Schatz, 2007; Syssner and Siebert, 2020). The existence in northern Europe and the Mediterranean countries of large areas with a low population density means that scenarios are required in which these areas are given priority treatment when planning for and allocating funds from the next Cohesion Policy (2021-2027). This demand comes from the European Committee of the Regions, the Demographic Change Regions Network and the Northern Sparsely Populated Areas network (EU, 2016; Ruiz and Cañizares, 2020), which advocate making rural depopulation the central focus of cohesion policy. Addressing depopulation was a topic discussed by the European Parliament in February 2019, when it was agreed that each state in the Union should receive $5 \%$ of these funds, to be devoted to areas in demographic crisis during the next financial period.

Spain is an example of a Mediterranean country that has undergone large-scale rural depopulation, especially since the second half of the 20th century. The population living in rural municipalities has shrunk by almost five million people since 1950, from $40.3 \%$ of the total population to only $12.1 \%$ of the total in 2018, according to official population censuses. At the spatial level, this process has resulted in an emptying out of the interior of Spain and an increase in the density of the periphery and major urban areas (Molinero, 2019). Far from being a trend limited to previous decades, municipalities with a lower population density are continuing to lose population. Based on the latest population data published in Spain, areas with less than 10 inhabitants $/ \mathrm{km}^{2}$ have lost $23.1 \%$ of their population over the last ten years, while in some regions, such as Galicia, in the north-west of the Iberian Peninsula, the population has fallen by $38.8 \%$ over the same time period. This delicate situation has made depopulated Spain a topical issue, due to its social, economic and political significance. In fact, the Government Commission for the Demographic Challenge and the Ministry for the Ecological Transition were created in 2017 to specifically address these problems. The general framework is based on a set of proposals for correcting demographic imbalances in coordination with other institutions and administrations, such as the Autonomous Regions, the Spanish Federation of Municipalities and Provinces and local action groups working as part of the LEADER initiative. These multilevel cooperation schemes advocates exploring the possibilities offered by the European cohesion funds to improve the provision of basic services, diversify economic activity, enhance the cultural value of many agricultural landscapes and, above all, focus on accessibility as a vector of social and economic dynamism, as will be seen in the territory studied.

The next section set the theoretical base of the investigation, rooted in the accessibility analysis for rural areas. Section 3 unfolds the procedure of the investigation, introducing in the first place the study case selected to test the hypothesis and then exploring the methods applied. Section 4 contains the results, summed up following the steps presented in the methods part. Finally, the last sections are the discussion and conclusion.

\section{Rural accessibility: a theoretical framework}

Accessibility is a concept academically ambiguous, studied using different viewpoints. The gravity approach is one that is used more frequently, that connects with Newton's law of gravitation where interaction (attraction) is directly proportional to the population (mass) and decays with distance (Lenormand et al., 2016). The gravity models, also called potential accessibility models are included within the location-based accessibility measures according to Geurs and van Wee (2004), which focus on movement costs or friction between locations. From a synthetic perspective, it relates to the potential access of the population to opportunities, with 
the understanding that there is a separation between the opportunities and the needs of the population. This separation is primarily understood in physical terms; however, physical distance is only one of several possible aspects when assessing accessibility, although probably the one with the most impact in general terms (Kanuganti et al., 2015: 312), and it is also possible to establish others of a social or economic nature (religion, purchasing power, income, status, etc.). It is such a broad and diverse concept that an effective theoretical approach is essential to define it within the framework of an empirical application like this one.

In the rural context, accessibility has been a central concept for decades: it was identified by Moseley as a key variable in a rural reality increasingly separated from services and opportunities located in urban centres (Moseley, 1979). Wiggins and Proctor pointed out three main features of rural areas: the abundance of land, a significant distance with urban areas, and a considerably lower income rate (2001: 428). The proximity to the urban areas is a key element to determine the characterization of rural areas, meaning that distance is meaningful to understand economic and social implications for rural areas. Rural dependence is a process that has become increasingly accentuated, especially in areas with greater physiographical difficulties in achieving integration (Dunaway, 1996), accentuating dependence and emphasising the role of accessibility as an integral problem (Farrington and Farrington, 2005). In addition, an inverse correlation of factors between rurality and accessibility has been determined (Morrissey et al., 2008): the greater the accessibility, the less rural is the area. Polarization is a strong feature associated with the urban areas, leading to a peripheralization process in rural areas which strengthen the unbalance and centre-periphery division (Kühn, 2015: 367-368), enhancing the problem for rural areas to connect to the main dynamics.

A common problem in areas with low population density and the predominance of extensive activities is the difficulty in reaching demand thresholds for implementing services, including transportation services (Peacock and Pemberton, 2019). This leads to dependence on two levels: a) external, for satisfying needs (services, consumer goods, employment and economic opportunities), and b) internal, as collective transport options disappear almost completely. The logic of the market produces a growing physical separation between rural spaces and service and product centres, which makes mobility in these areas a key factor for understanding the dynamics of the spaces. The options for meeting this need for mobility decrease, as public transport has difficulty in meeting profitability criteria in these territories (Neumeier, 2016), and, in Europe, rural mobility depends almost exclusively on private vehicles (Vitale and Cotella, 2020). The distance tends to grow, either because of fewer opportunities or because of a progressive shift away from dynamic centres in a process that feeds back into increased levels of individual mobility (Lopez-i-Gelats et al., 2009).

For the purpose here, it is interesting to approach the concept of rurality through territorial integration, which in short, leads to participation in the economic and territorial system. In Europe, spaces with a widely dispersed, sparse population tend to have an economic growth below the EU average (Gáková and Dijkstra, 2010) and those with the best results are the ones that participate in market processes because their production has adapted to it or they are spaces that, due to their closeness, are integrated into urban dynamics.

For this reason, most rural accessibility studies focus their efforts on characterising the ability of these territories to connect with cities in the urban system with very different objectives: they use it as a criterion for differentiating the profile of rural territories (Barnett et al., 2001; Caschili et al., 2015; Martinez, 2018); as a method for understanding the diversity of their dynamics in relation to a key factor for their economic development (Vickerman, 1995): implications for ageing (Ahern and Hine, 2015; Ranković and Jović, 2018) or gender (Adom-Asamoah et al., 2020); or to analyse the lack of access to community services, especially healthcare (Ahern and Hine, 2015; Kanuganti et al., 2015; Morrissey et al., 2008; Murawski and Church, 2009; Shah et al. 2017); access to essential goods (Mu et al. 2020; Yeager and Gatrell, 2014); or changes in the functioning of markets such as housing (Smith et al., 2012).

These studies focus on an applied and empirical approach to the concept that searches to describe and interpret a situation that depends on spatial configuration, usually branching out into the legislation on accessibility to demonstrate which changes to the configuration of spaces would 
improve the empirical results (Levine, 2020). They propose a scenario in which rural areas are at a disadvantage and the characteristics of access to goods and services become a structural element that forms part of the rural condition itself.

For this reason, accessibility is included, in one way or the other, in the indicators of rurality and into the empirical studies that seek to diagnose the territorial situation of these environments. The integration of low-density spaces into the urban and/or metropolitan reality is a narrative that is addressed with some frequency. The European Union Statistical Office (Eurostat) differentiates between rural areas and urban areas by following the OEDC criteria (OECD, 1994) that, to define a profile, establish the need to supplement the demographic indicator (population density below 150 inhabitants $/ \mathrm{km}^{2}$ ) with an indication of proximity to urban areas. The resulting criterion is the degree of urban-rural connection, differentiating between rural spaces that are integrated into metropolitan areas, rural areas with a good connection to medium-sized urban centres and rural spaces with a very low ability to connect to the urban fabric (Brezzi et al., 2011). It is not strictly a criterion of accessibility but of cohesion in relation to urban spaces, which talks of urban domination on a regional scale composed of heterogeneous spaces in a functional hierarchy (Cloke, 2006) that determines the development of the territories (Isserman, 2005).

Distance is often the key factor in analyses when measuring cohesion in relation to proximity to more dynamic environments. This leads to a tendency to interpret proximity as an indicator of accessibility, without always considering other elements related with effective access, especially if the specific difficulties of rural mobility, such as vehicle dependence or ageing (Terluin, 2003) are considered. Recent studies have also found that the pattern for the location of certain activities does not have a linear correlation with demographic patterns, nor with distance in an absolute sense, and different dispersion models have been produced depending on whether these are commercial (supermarkets), healthcare or education services (Christiaanse, 2020). An analy sis of this context necessitates a reinterpretation of the concept of distance and closeness and a more precise analysis of the accessibility conditions of rural spaces and their cohesion in the territorial system.

\section{Case study and methodological procedure}

The methodology is divided into three distinct parts. Firstly, the territory to be studied is assessed, justifying its choice and its suitability for a study of accessibility. Secondly, the aspects to be taken into account in the demographic analysis are briefly discussed, while the methodology for analysing accessibility is presented in the third section.

\subsection{Case study: The province of Guadalajara (Spain)}

Guadalajara is a province (NUTS3) in the centre of Spain belonging to the Autonomous Region of Castilla-La Mancha (ES424), geographically adjacent to Madrid and in the corridor connecting Madrid and Barcelona (Figure 1). The area connecting Madrid and Guadalajara is called the Henares Corridor, and it is one of the spaces with the greatest intensity of urban and industrial expansion and spread on the Iberian Peninsula. This province was chosen for this case study as it combines several useful characteristics for testing the working hypothesis, since it illustrates the difference between the concepts of proximity and accessibility, which is especially significant when applied to rural environments. Guadalajara is a province with a strongly rural character: only 3 of its 289 municipalities are statistically urban and 11 are intermediate (over 2,000 inhabitants), leaving a balance of 275 rural municipalities in the province. Due to its geographical position, it can also be considered a territory close to dynamic spaces and corridors, given its proximity to Madrid, allowing the conditions for accessibility to be related to demographic behaviour.

In various Europe-wide studies, Guadalajara has been assigned an optimal accessibility result, due to a scale factor that benefits central positions, like the one it enjoys, as compared to others of a peripheral nature in the EU context (Ballas, et al., 2003; Spiekermann and Wegener, 2003; Vickerman et al., 1999). In these analyses, the province offers good data in terms of access times, and even an intermediate profile in terms of rurality (van Eupen et al., 2012: 474), with a notable improvement in accessibility in recent decades (Holl, 2007; Martinez et al., 2014). 
This result is due to the scale of these analyses, which include a broad sample from all over the EU. Guadalajara and its proximity to the centre of the Iberian Peninsula and Madrid have a positive effect compared to other peripheral areas in the Union. In terms of distance, the province of Guadalajara cannot be considered to be inaccessible, since much of it is located on the Madrid-Barcelona axis, an important one in Spain, and it benefits from strategic, highcapacity infrastructure (motorways and the AVE high-speed train). Its proximity to Madrid constitutes a metropolitan corridor with extensive economic activities around the communications axis and with good transport services in this corridor.

However, this assessment hides a more complex reality. While it can be said that the province has a degree of proximity in its territorial context, this does not lead to the effective integration of the entire provincial space, since the province presents patterns of rurality and peripherality comparable to more distant areas in other contexts. For this reason, Guadalajara province is an ideal case study for testing the original hypotheses.

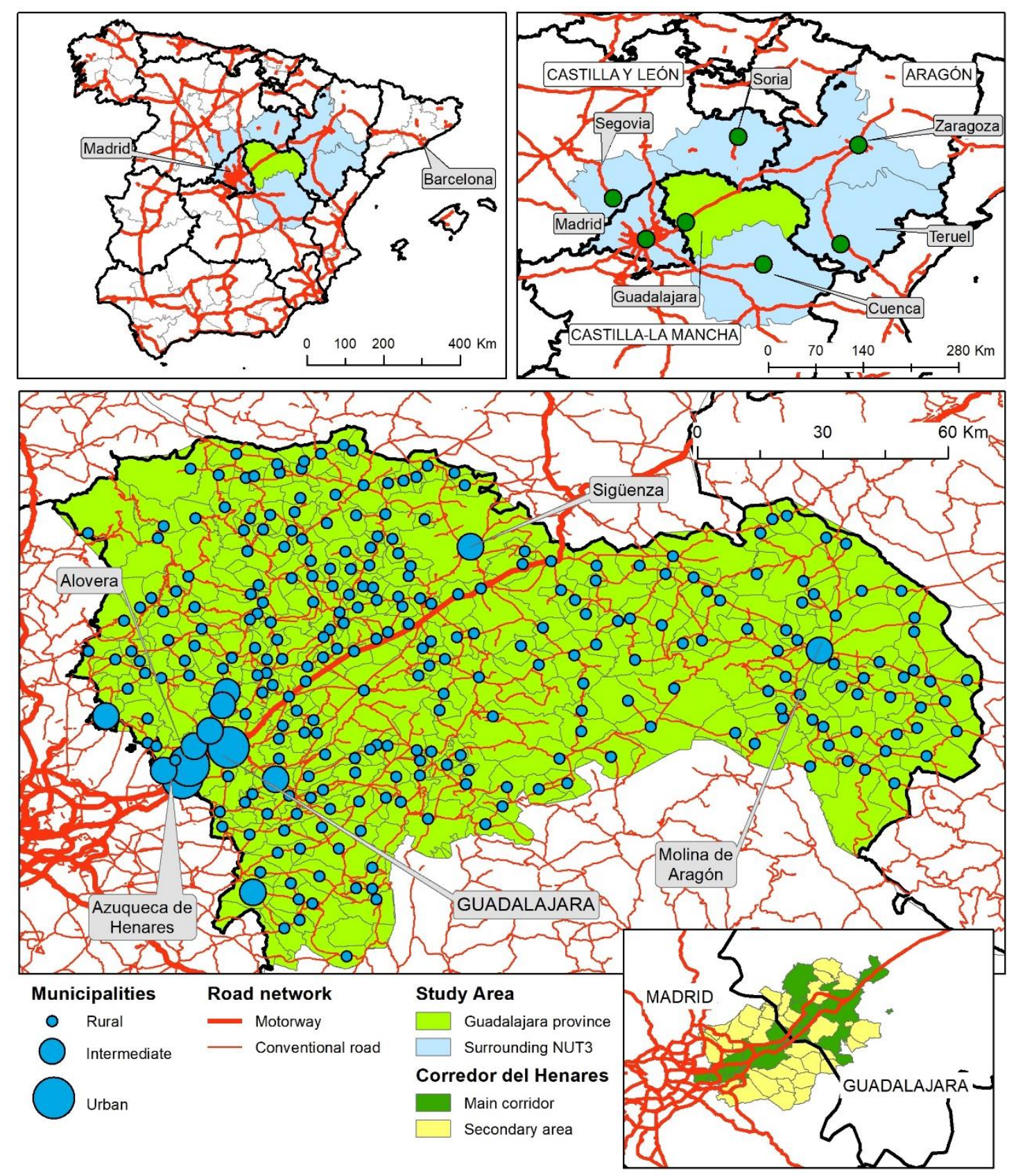

Fig 1. Study area. Source: CNIG, INE. Own elaboration 


\subsection{Methods for demographic analysis}

In this part, a demographic analysis is proposed by taking both a diachronic and synchronous view of the phenomena affecting the behaviour and characteristics of the population. This is a multidisciplinary framework in which depopulation is approached from a social, demographic and geographical perspective, using the tools needed for its calculation and its graphic and cartographic representation.

The demographic analysis was conducted in two stages: the first was the collection of data from official bodies, using published and unpublished official statistical sources from the Spanish National Institute of Statistics (INE). These data respond to the three essential criteria for demographic analysis: natural dynamics, represented by the municipal Population Register; spatial dynamics, based on Residential Variation Statistics; and demographic characterisation, based on several different sources, the Population Census being the most important. They all have a high degree of reliability because they are produced by official agencies and are easily accessible. The only limitations are the inadequate temporal depth of the Population Census, which will only be updated in 2021, and the fact that no up-to-date data exists on villages or other population groups considered on a territorial scale as below municipalities.

The second stage consisted of obtaining municipal indicators that would help to interpret the phenomenon of a falling population and depopulation over a defined period. To measure population loss, we studied the demographic change found in the long term (since the beginning of the twentieth century) and in the medium term (last twenty years), for a better causal interpretation of the phenomenon. This issue is central to demographic analysis, which is heavily influenced by the cyclical effects of social and economic factors. The medium-term study reduced the misinterpretation of indicators obtained during periods with special economic and social circumstances, such as those following the 2008 financial crisis. To measure the degree to which the population has fallen, out of the different methods for analysing population variation, the Annual Growth Rate (AGR) proposed by the United Nations was chosen, which brings together the components of natural (births and deaths) and spatial (migrants and immigrants) dynamics within a defined time interval. In this report, the constant annual growth rate was used, which is usually employed by the UN and is formulated as follows:

$$
\mathrm{AGR}=\left(\sqrt[t]{\frac{P f}{P i}-1} * 100\right)
$$

Where AGR is the constant real annual growth rate as a percentage, $t$ is the time interval, $P f$ is the final population and $P i$ is the initial population. This formula has been used to delimit municipal behaviour ranges for the last twenty years. As can be seen, demographic change is the final result of a combination of elements relating to natural and spatial dynamics, whose relationship reveals a definite demographic structure. The two dynamics are based on two basic indicators, natural growth, or the difference between births and deaths over a time interval, and the migration balance, the result of those recorded as moving into and out of a specific territory over a specific period.

In contrast, the study of depopulation is mainly based on an analysis of population density. This section will approximate the demographic change in municipalities with fewer than 8 and 12.5 inhabitants $/ \mathrm{km}^{2}$, which are the thresholds proposed by the European Union for NUTS-2 and NUTS-3.

\subsection{Accessibility analysis: spatial separation model}

When formulating the hypothesis, a dichotomy was proposed between proximity and accessibility, in which the first concept represents the position of a given point within the space analysed and the second is a more elaborate expression of that position. This term is related to spatial interaction models that define accessibility as a potentiality and the ability to access opportunities (Hansen, 1959). It is a characteristic that evaluates the configuration of the territory and the location of elements and activities in relation to a sample. 
When selecting the case study, the proximity of Guadalajara to the Madrid metropolitan area was established first, as the province should be situated in one of the most dynamic axes in Spain. The purpose of exploring accessibility in this context is to obtain a more accurate picture of the situation for each municipality in the province, so spatial separation was used, making the distance between origin and destination the variable for evaluating the accessibility conditions within the sample (Curtis and Scheurer, 2010). This is rooted with gravity and spatial separation models work with measurements that focus on the constraints of distance, measured using Euclidean distances, travel times (by mode of transport or type of road), travel costs or measuring service quality (for collective transport) (Bhat et al., 2000). The advantages of these models are basically twofold: the ease of obtaining information, which is why they are suitable for large, heterogeneous samples; and secondly, the simple interpretation of the results. Establishing measurements of this type within a continuous scale of analysis provides a measurement of potential accessibility, which tries to evaluate the potential of the locations within the sample analysed (Geurs and van Wee, 2004).

The basic formula for these models is a mathematical expression in which the result symbolises attraction and/or an opportunity for spatial interaction between two distant points. The accessibility of a point within the sample is the result of its attraction to destinations. The attraction will be directly proportional to an opportunity factor and inversely proportional to the function of the distance between each pair of points in the system. Distance is friction to movement, reducing the attractiveness of the opportunities available as it increases. This simple formula evaluates the balance between the potential for spatial interaction as a function of attractiveness versus the physical separation between the point of origin and the destination. The potential for attraction can be taken into account in a variety of ways, usually with a variable that expresses the capacity for attraction, such as the labour market, functional specialisation or economic parameters (Martínez et al., 2014; Mohíno et al., 2016; Mohíno, Ureña and Martínez, 2014).

In the empirical design of this analysis, the potential for interaction was taken as qualitative, by incorporating a matrix of destinations that define spatial attraction within a territorial system: urban spaces, health services and educational services. These three aspects are considered three different components of an integrated accessibility measure. The accessibility to these destinations was evaluated, distributed unequally across the territory, from the different municipalities in the sample, incorporating the ideal travel time as a quantitative variable, using the general equation (Geurs and van Wee, 2004):

$$
P A_{i}=\sum_{j}^{n=3} o_{j} f\left(d_{i j}\right)
$$

The potential accessibility $\left(P A_{i}\right)$ of each municipality $i$ in the sample is the sum of the opportunities $O_{j}$ to access urban, health and educational centres $(n=3)$ measured as the cost of moving between $i$ and $j$, in this case, the friction for the distance represented by the function $f\left(d_{i j}\right)$ :

$$
f\left(d_{i j}\right)=t_{i j}^{-\beta_{j}}
$$

This is a function of distance, represented in logarithmic form to express the progressive decrease in attraction as the distance increases and with a sensitivity parameter $\beta_{j}$ that includes the difference in attraction of each destination (Reggiani et al., 2011).

The specific indicator used for calculations is set as:

$$
\operatorname{Acc}_{i}^{U r b, H e a l t h, E d u}=\sum_{j}^{n=3,2,2} O_{j} * t_{i j}^{-\beta_{j}}
$$

$O_{j}$ stands for the opportunities (attraction) and $\beta_{j}$ is a sensitive parameter to module distance (friction of movement), which vary according to each accessibility component. The latter parameter enhances the friction in values above 1. Table 1 shows the criteria used to set both elements on each accessibility measure: 
- Acc Urb: The potential for access to urban environments was used as a variable for the availability of goods and services, for insertion in a territorial model that prioritises opportunities in relation to the configuration of urban networks. The access time to the nearest city was calculated, dividing them into three types: level 1 (over 100,000 inhabitants), level 2 (from 50,000 to 100,000 inhabitants) and level 3 (from 10,000 to 50,000 inhabitants).

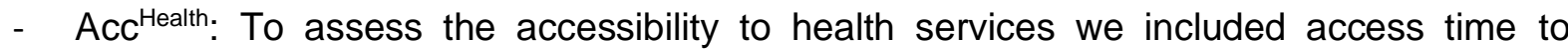
hospitals as specialised services and health centres as basic services.

- Acc Edu: The educational services include access to university campuses as a specialised service and secondary schools, which we considered a basic educational service.

The combined accessibility of each point in the sample is, therefore, the sum of three components normalised using the Z-score method: the assessment of access to urban spaces, access to health services and the availability of educational services, so that it is possible to reformulate the expression as follows:

$$
A T o t_{i}=Z A c c_{i}^{U r b}+Z A c c_{i}^{\text {Health }}+Z A c c_{i}^{E d u}
$$

The way the Z-indices are calculated for each component is:

$$
Z_{x}=\frac{X_{i}-\bar{X}}{\sigma}
$$

Where $Z x$ is the $Z$ index (calculated for each accessibility component " $x$ "), which is the result of the average for the sample subtracted from the result for each sample $i$ divided by the standard deviation. The result of applying this technique gave standardised results, with an average equal to 0 and a variance of 1 , which made it possible to compare the results for the different accessibility components with each other and to integrate them in a balanced way, regardless of the numerical value that each calculation may receive, as seen below.

Tab 1. Building the accessibility database. Source: Own elaboration, CNIG: National Centre for Geographical

\begin{tabular}{|c|c|c|c|c|c|}
\hline Factor & Source & Type & \multicolumn{3}{|l|}{ Variable } \\
\hline $\begin{array}{l}\text { Municipalities } \\
\text { analysed in the } \\
\text { sample }\end{array}$ & CNIG, BCN 200,000 & Point & \multicolumn{3}{|l|}{ Location } \\
\hline Urban base & CNIG, BCN 200,000 & Point & $\begin{array}{r}\text { Location: } \\
\text { Level } 1 \\
\text { Level } 2 \\
\text { Level } 3 \\
\end{array}$ & $\begin{array}{l}\boldsymbol{O}_{\boldsymbol{j}} \\
\text { Population }\end{array}$ & $\begin{array}{l}\boldsymbol{\beta}_{j} \\
1 \\
1.25 \\
1.5 \\
\end{array}$ \\
\hline Health services & $\begin{array}{l}\text { CNIG, BCN 200,000 } \\
\text { Spatial Data } \\
\text { Infrastructure for the } \\
\text { following } \\
\text { communities: Aragón, } \\
\text { Castilla y León, } \\
\text { Castilla-La Mancha } \\
\text { and Madrid }\end{array}$ & Point & $\begin{array}{l}\text { Location: } \\
\qquad \text { Hospitals } \\
\text { Health centres }\end{array}$ & $\begin{array}{l}O_{j} \\
\text { Nr. beds } \\
1\end{array}$ & $\begin{array}{l}\boldsymbol{\beta}_{j} \\
1 \\
1.25\end{array}$ \\
\hline $\begin{array}{l}\text { Educational } \\
\text { services }\end{array}$ & $\begin{array}{l}\text { CNIG, BCN 200,000 } \\
\text { Spatial Data } \\
\text { Infrastructure for the } \\
\text { following } \\
\text { communities: Aragón, } \\
\text { Castilla y León, } \\
\text { Castilla-La Mancha } \\
\text { and Madrid }\end{array}$ & Point & $\begin{array}{l}\text { Location: } \\
\text { Universities } \\
\text { Secondary } \\
\text { schools }\end{array}$ & $\begin{array}{l}\boldsymbol{O}_{j} \\
\text { Nr. degrees } \\
1\end{array}$ & $\begin{array}{l}\boldsymbol{\beta}_{j} \\
1 \\
1.25\end{array}$ \\
\hline Road network & CNIG, BCN 200,000 & $\begin{array}{l}\text { Line } \\
\text { (network) }\end{array}$ & \multicolumn{3}{|c|}{$\begin{array}{l}\text { Potential travel time (minutes): } \\
\text { Motorway, } 120 \mathrm{~km} / \mathrm{h} \\
\text { Conventional road level } 1,100 \mathrm{~km} / \mathrm{h} \\
\text { Conventional road level } 2,80 \mathrm{~km} / \mathrm{h} \\
\text { Conventional road level } 3,60 \mathrm{~km} / \mathrm{h}\end{array}$} \\
\hline
\end{tabular}
Information (www.cnig.es). BCN: National Cartography Base 
To obtain this data, a GIS database was built using a variety of sources (Table 1), which was supplemented by using the transport network from the Spanish National Cartographic Base, updated to 2019, which was processed using the Network Analyst extension from ArcGIS 10.3 software, ranking each network by category, and implementing the speed of each section according to it (Table 1). With the database built and operational, the different indicators were calculated and the results obtained. Working with layers of information also makes it possible to analyse each component separately, which can be useful when interpreting the results.

\subsection{Combining demographic analysis and accessibility}

The last analytical process carried out focused on checking the relationship between the demographic results and accessibility, both in combination and for the three components calculated. To do this, a bivariate correlation analysis was made between the demographic and accessibility results. The results obtained in both areas showed a non-normal distribution, with extreme values that require the use of a non-parametric correlation technique adapted to this distribution, such as Pearson's correlation coefficient (Rogerson, 2006: 154-157):

$$
r=\frac{\sum_{i=1}^{n}\left(Z_{x} * Z_{y}\right)}{n-1}
$$

The correlation $r$ is the result of comparing the two variables $x$ and $y$ in their standardised form, $Z_{x}$ and $Z_{y}$ respectively, across the sample of $n$ values for each case $i$. Pearson's correlation has the property that its value varies between +1 and -1 , the first case being the maximum positive correlation (high values for variable $x$ correspond to high values for variable $y$ ) and the second the maximum inverse correlation (high values for one variable correspond to low values for the other). Values close to 0 indicate that there is no statistical correlation between variables $x$ and $y$.

This type of calculation was accompanied by a significance test to check that the result of each variable was independent and that an observation recorded on one of them did not statistically affect the results for any other variables. Both the calculation of the coefficient and the significance testing were performed using the IBM SPSS Statistics 24.0 statistical software.

\section{Results}

The results section is divided into three separate areas, which helped to structure the analysis of the data obtained in the empirical process described above. Firstly, the socio-demographic context of the province is presented and then an analysis of the results of the accessibility calculations obtained. Lastly, the aspects (demography-accessibility) are combined to test the original premises.

\subsection{Relevant demographic aspects}

Guadalajara province reflects many of the major demographic trends that are affecting the regions of inland Spain: a dispersed population, where $89 \%$ of the municipalities are below 1,000 inhabitants; a continuous decline in the rural population over decades; and a significant imbalance in its age structure, which is more pronounced in the more rural areas, characterised by a shortage of young people and a progressive increase in the population aged over 65.

\section{Demographic dispersion}

The main demographic feature of Guadalajara province is the significant dispersion of its population, with very sparsely populated areas. It is one of the least densely populated areas in Spain, which has led to its being called the "Spanish Siberia" or the "ground zero of European Union depopulation" (Ruiz and Cañizares, 2020). The level of dispersion reached, which can be seen in Table 2, puts a significant brake on territorial structuring and aggravates various demographic imbalances, especially those related to natural (births and deaths), spatial (rural 
migration) and age structure (ageing) dynamics. $48 \%$ of the area of the province contains only $2.6 \%$ of the total number of inhabitants. Using the European population density thresholds set for NUTS-3 units (below 12.5 inhab. $/ \mathrm{km}^{2}$ ), it was confirmed that $87.4 \%$ of this territory can be defined as sparsely populated.

Tab 2. Population density by number of municipalities and total extension (2019). Source: Spanish National Institute of Statistics (INE) (own elaboration)

\begin{tabular}{|l|c|c|c|c|}
\hline & $\begin{array}{c}\text { Number of } \\
\text { municipalities }\end{array}$ & $\begin{array}{c}\text { Province } \\
\text { Area (\%) }\end{array}$ & $\begin{array}{c}\text { Population } \\
\text { (Inhabitants) }\end{array}$ & $\begin{array}{c}\text { Population } \\
\text { (\%) }\end{array}$ \\
\hline$<2$ inhabitants/Sq & & & \\
\hline $\begin{array}{l}\text { Between 2 and 8 } \\
\text { inhabitants/Sq }\end{array}$ & 126 & 47.9 & 6.561 & 2.6 \\
\hline $\begin{array}{l}\text { Between 8 and 12.5 } \\
\text { inhabitants/Sq }\end{array}$ & 107 & 28.0 & 13.308 & 6.9 \\
\hline $\begin{array}{l}\text { Between 12.5 and 30 } \\
\text { inhabitants Sq }\end{array}$ & 18 & 11.5 & 13.493 & 3.7 \\
\hline $\begin{array}{l}\text { Between 30 and 100 } \\
\text { inhabitants Sq }\end{array}$ & 10 & 4.4 & 9.149 & 3.6 \\
\hline$>100$ inhabitants/Sq & 13 & 3.9 & 23.240 & 9.1 \\
\hline
\end{tabular}

The choice of Guadalajara province for the study of rural accessibility was therefore justified by the strong significance of these depopulated areas that coexist, in a relatively close space, with areas with a large population. A series of municipalities, located within the area of influence of the Madrid metropolitan area, accounts for almost a third of the population in only $4.3 \%$ of the territory (Figure 2). Here, the average population density is more than 390 inhabitants $/ \mathrm{km}^{2}$, comprising municipalities with demographic dynamics markedly different from the rest of the province. In this range, of more than 100 inhabitants per square kilometre, the weight of Guadalajara (capital) and Azuqueca de Henares stands out, as they alone account for $46.9 \%$ of the total population. Therefore, in addition to the spatial contrast offered by the disparate population density, there are also the imbalances inherent in the administrative organisation, since almost half of the provincial population is concentrated into two municipalities, while 268 municipalities, $92.3 \%$ of the total, contain only $16.9 \%$ of the population.

The map in Figure 2 highlights the geographical extent of areas with fewer than 8 inhab/km² throughout the province. In general, these are places where orographic, biogeographical and edaphic factors have prevented the development of significant human settlements, especially in the mountainous areas in the north-west and east of the province (central system and lberian system). In the central parts of the province, corresponding to the natural regions of the higher and lower Alcarria, the limitations stem from the climatic and soil conditions of the paramera high plains. In these areas, the extreme climatic variations and soils poor in organic matter result in low productivity, the main factors limiting demographic development. Here, the economic base continues to be linked to rural, forestry and livestock activities, among which rural tourism is gaining weight. These are areas of demographic desert, in which the larger, but scattered towns act as regional centres. Municipalities like Molina de Aragon (in the east) or Sigüenza (in the north) play an important role as centres providing essential services for their areas of rural influence.

The highest population densities correspond to the western part of the province, where the importance of the "Henares Corridor", the industrial axis that crosses the provinces of Madrid and Guadalajara from west to east and has a level of social and economic development that is distinct from the rest of the province, is notable. In this strip, the importance of the city of Guadalajara $(85,871$ inhabitants in 2019) and the industrial and service activities undertaken along the Corridor, which have seen significant capital investments in recent years, should be noted. Its origins lie in the development of industrial land around Madrid that has taken place 
since the 1940s (Diaz et al., 2002; Del Río and Rodríguez, 2009: 140-141). In addition, since the nineties, it has benefited from the phenomenon of industrial relocation to rural environments, to take advantage of the competitive opportunities offered by the latter in terms of the availability of industrial land and labour. In the case of Guadalajara province, the industrial relocation commonly seen in the restructuring of economic activities resulting from globalisation, has been called the peripheralisation or spatial diffusion of industrial growth resulting in urban and demographic development (Diaz et al., 2002: 306).

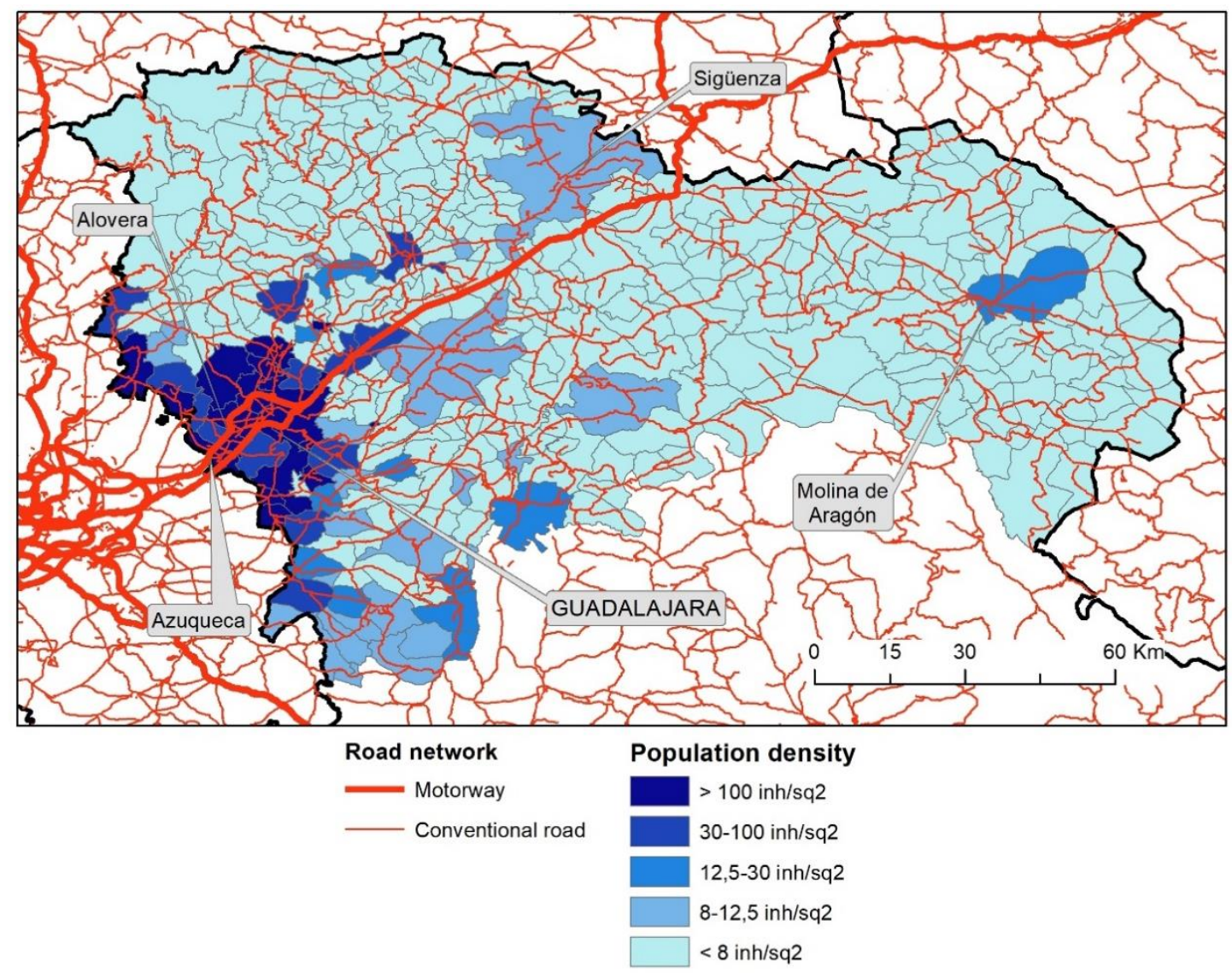

Fig 2. Population density at municipal level Source: CNIG, Databases from Autonomous Regions (see Table 1). Own calculations and elaboration

\section{Demographic change and its impact}

The unique geographical features found in Guadalajara province mean that the depopulation described above is a clearly a centuries-old phenomenon, i.e., a settlement pattern that has been perpetuated throughout history without too much oscillation in population levels. The economic and social conditions of the past and present century have conditioned the population model, as has been seen, and the rate of population variation, aggravating the territorial imbalances in the province. The population variation model is summarised in Figures 3 and 4 , in which it can be seen that the province as a whole is gaining population, while its rural municipalities, especially the smaller ones, are remaining stagnant or losing population.

Figure 3 shows the change in real annual growth from 1900 to the present. In general, this trend is similar to those in most other Spanish rural regions: firstly, stagnant or weak growth up to 1950; secondly, an accelerated decline between 1950 and 1981 motivated by the migration of the rural population to the cities, in a phenomenon commonly known as the "rural exodus"; and thirdly, demographic recovery since the 1980s. In the case of Guadalajara province, its recovery has the unique feature that it took place in a very rapid, even expansive, manner in the first decade of the 21 st century, coinciding with the industrial and urban consolidation of the Henares Corridor. The growth took place in small and intermediate towns and is particularly striking in some small rural municipalities. For example, the municipality of Yebes increased from 168 inhabitants in 
2001 to 3,791 in 2019; in other words, its population multiplied by a factor of twenty-two in just eighteen years. The real growth obtained is $9.3 \%$, an indicator barely comparable to those recorded in any other Spanish municipality for the same period. After 2011 this growth stagnated because of the economic crisis. The data on residential variations indicate that the number of those moving in, especially foreign citizens, has slowed, in a context where low fertility rates are widespread.

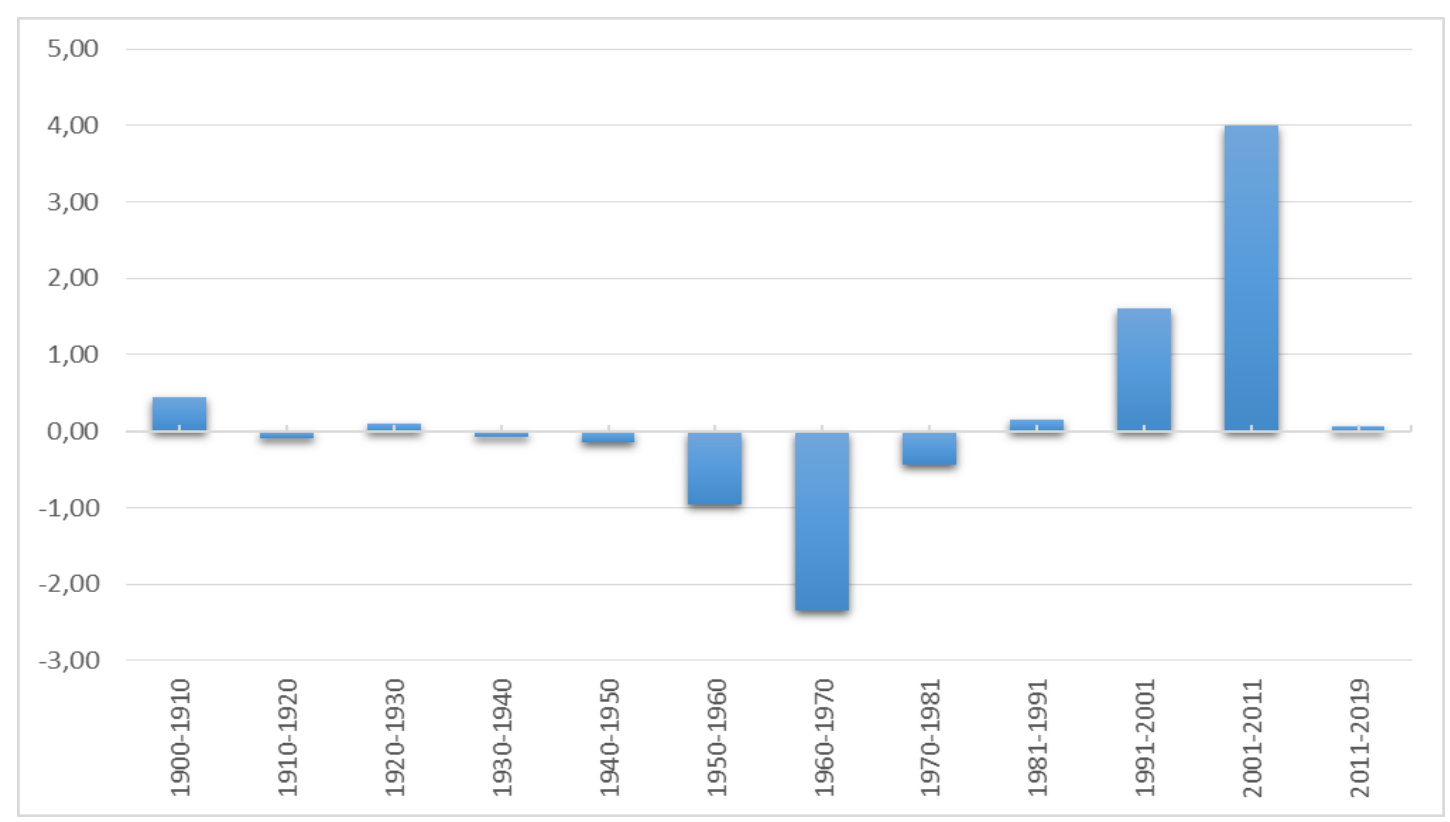

Fig 3. Evolution of the Real Annual Growth Rate (\%) in Guadalajara province (1900-2019). Source: Spanish National Institute of Statistics (INE). Own elaboration

The growth trend since 1991 offers a distorted picture of the provincial demographic reality as this increase was determined by the expansive behaviour of a limited number of municipalities. Municipalities with a very low population density, which account for more than $75 \%$ of the territory, have a markedly different trend. Figure 4 analyses the evolution of these municipalities at the time of the province's greatest demographic development (2001-2019).

Municipalities of this type did not take part in the real growth of more than $4 \%$ recorded for the province between 2001 and 2011. The trend for them has been to maintain a steady population, reproducing the same evolution since a long time ago. The effects of the economic crisis have especially been felt since 2011 . Between 2011 and 2019, the municipalities with a low population density lost 6,334 inhabitants, or about $30 \%$ of their workforce. This decline was due to the negative migratory balances occurring throughout the period, with the drop in fertility making it impossible to have any population growth. The absence of a fertile population aggravates the drop in fertility and conditions the increase in the elderly population, which in these municipalities is $38 \%$, on average.

To sum up, several paradoxical demographic trends coexist: dispersion versus concentration as shown by the map in Figure 2, and growth versus decline as shown in Figure 5 . Both maps show that these paradoxes take place in municipalities that are very close to each other. 


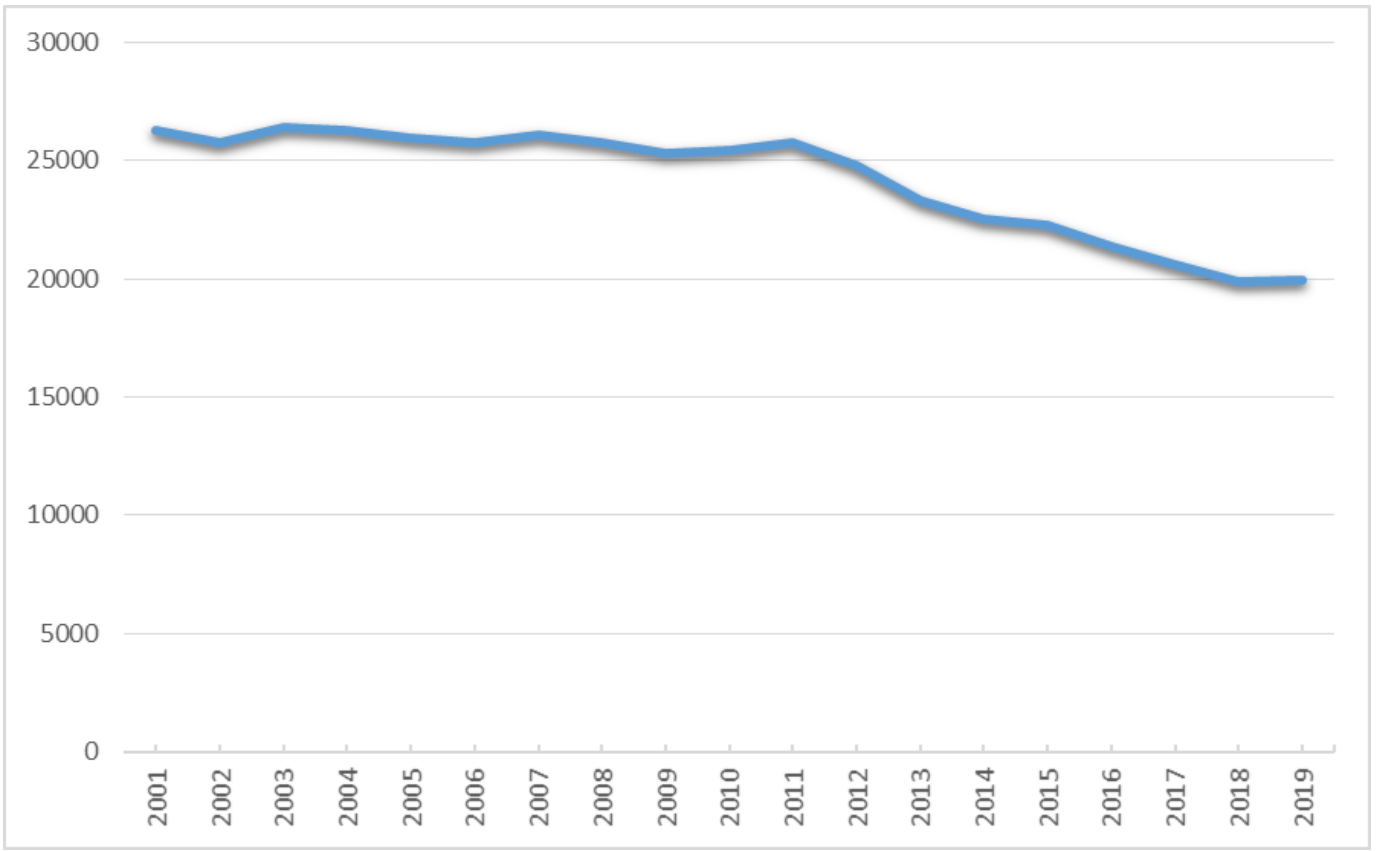

Fig 4. Evolution of the rural population (<8 inhab/ $\left.\mathrm{km}^{2}\right)$ between 2001 and 2019. Source: Spanish National Institute of Statistics (INE). Own elaboration

Figure 5 shows that an overwhelming majority of municipalities lost population between 2001 and 2019 , when the province attained its maximum population growth. There are strong differences in growth between the western part that borders Madrid and the rest of the territory. In the transitional space between the two areas, cases can be found that are particularly striking, since at a distance of only 30 kilometres, there are municipalities with more than $3 \%$ real growth, compared to others that are losing a significant proportion of their population. Logically, the greater the distance from Madrid and its area of influence, the lower the growth experienced and the lower the population density, so that the important role that rural accessibility can play in explaining these types of spatial anomalies can easily be inferred.

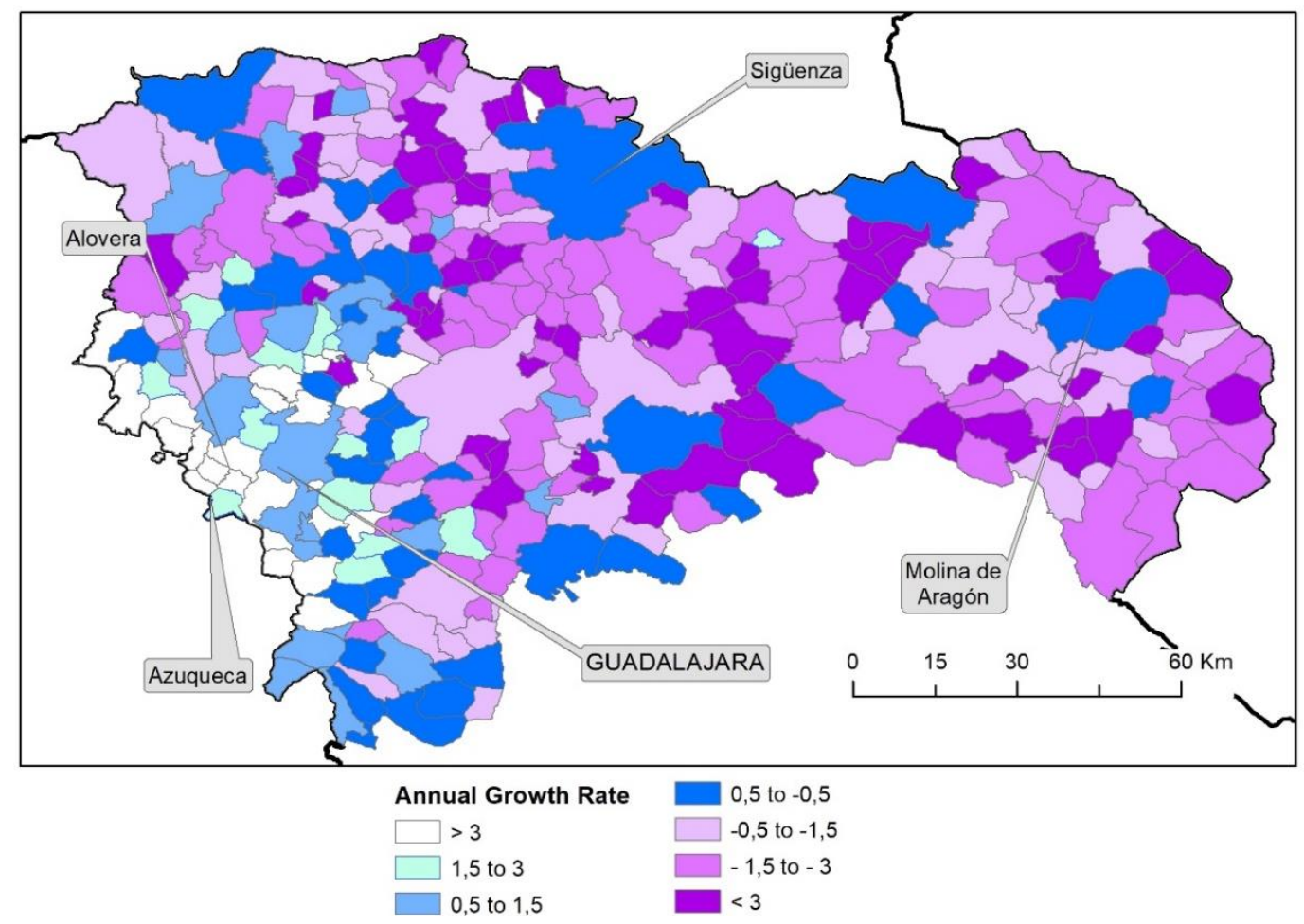

Fig 5. Real Annual Growth Rate (\%) in Guadalajara province (2001-2019). Source: Spanish National Institute of Statistics (INE), CNIG. Own elaboration 


\subsection{Accessibility: results}

Figure 6 shows the accessibility results in cartographic form, from which only the urban municipalities of Alovera, Azuqueca and Guadalajara have been excluded. The maps for each component represent the values grouped by quartiles, with the intention of showing population groups: the best results (the first quartile), those with good results (second), those with poor results (the third quartile) and the group with the worst figures (the last quartile of the distribution).

Figure 6.A shows the results for accessibility to urban centres, with the functional areas divided onto three levels, as seen in Section 3.2. There is a clear, positive, funnel-shaped gradient towards the provincial capital and, therefore, towards Madrid, showing the important polarising effect of this city and its metropolitan area. At the same time, the western end of the province shows good results, due to its proximity to surrounding provincial capitals. However, this effect is very limited across the territory, since it does not create a gradient towards the interior; on the contrary, after the group of municipalities with good results, there is a gap before the fourth group, with municipalities that are disadvantaged in their access to urban areas. Overall, the significant polarising effect of external urban spaces, especially Madrid and the Henares Corridor, generates significant inequalities in the municipalities that are not part of it.

A. Accessibility to urban areas

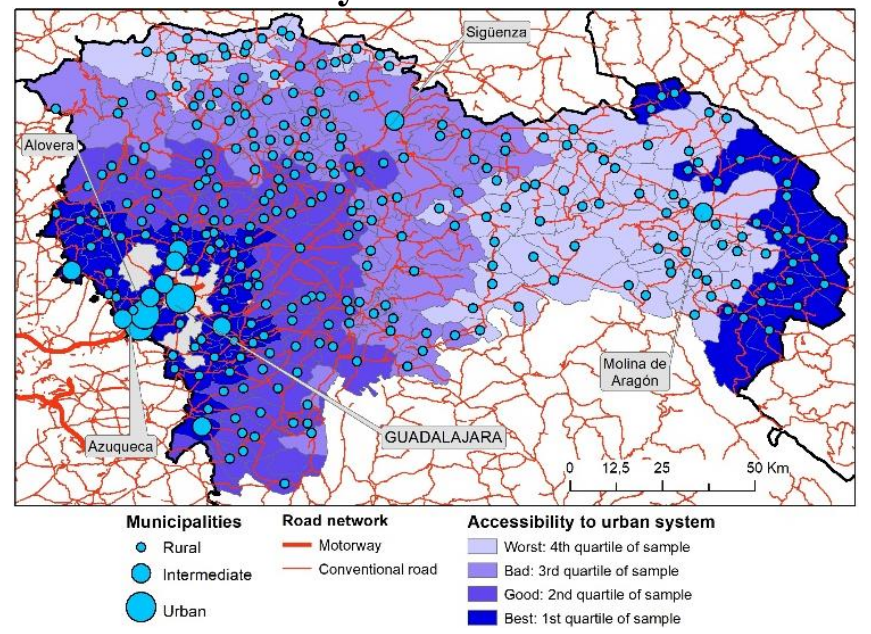

C. Accessibility to education centres

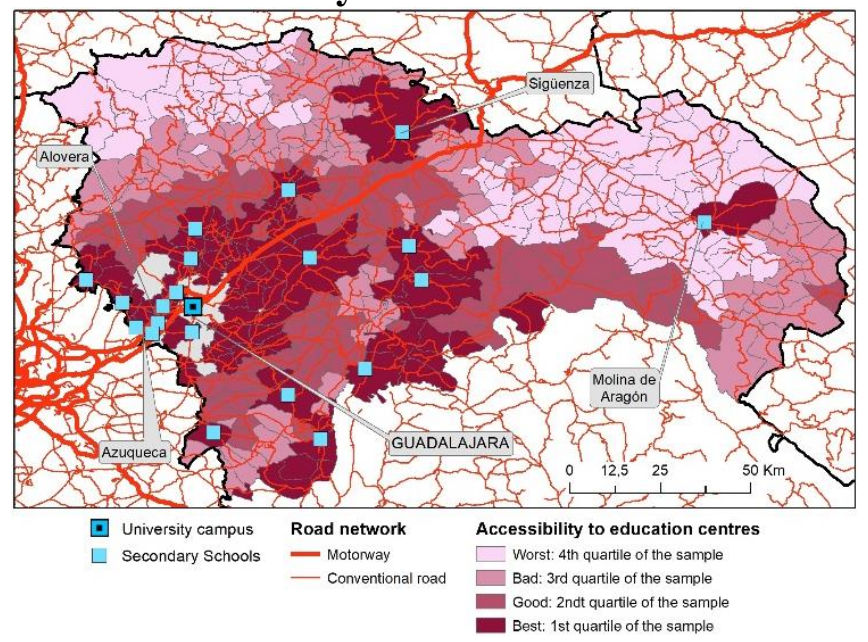

B. Accessibility to health care

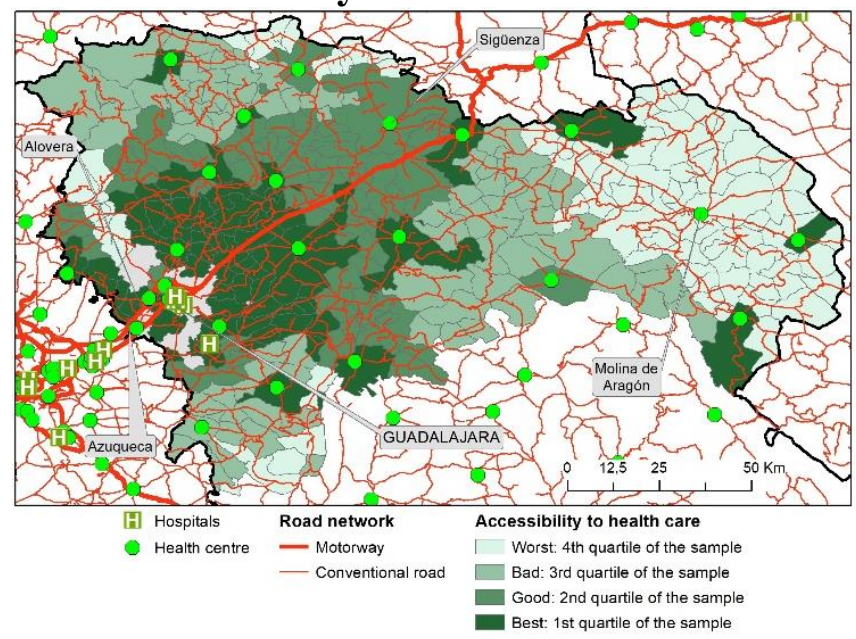

D. Accessibility combined

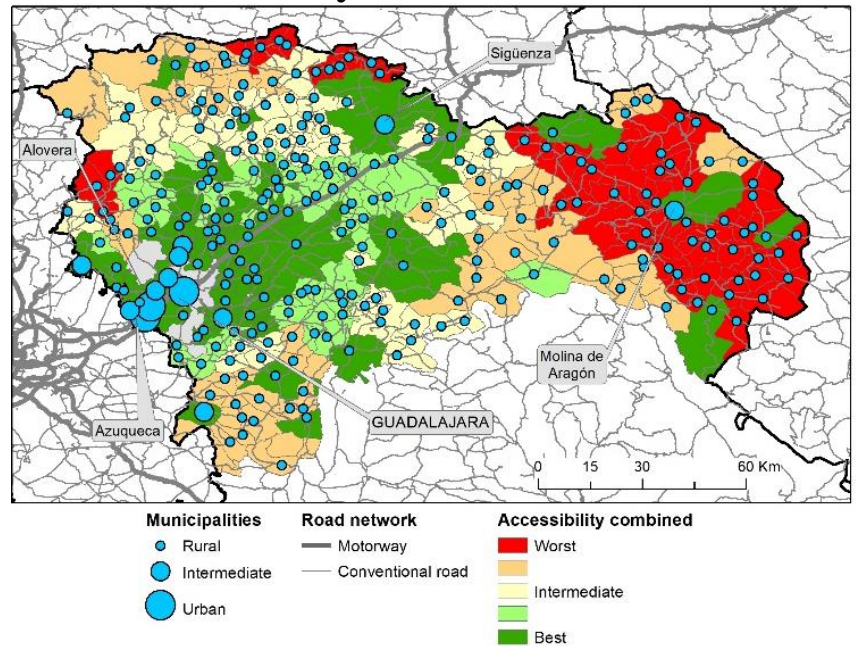

Fig 6. Accessibility results. Source: CNIG, Databases from Autonomous Regions (see Tab. 1). Own calculations and elaboration

Figure 6.B shows access to health services, ranked at two levels: specialised (hospitals, weighted by their level of capacity for care and specialities) and common (primary care centres). The result 
is similar to the previous one, showing the polarisation around the attraction of the Guadalajara (city)-Madrid axis, but it also shows the effect of the distribution of health centres in rural municipalities that act as county capitals. The map shows an area of great accessibility, with a gradient following the focus of the Henares Corridor, and scattered points with good accessibility as they contain a health centre (Distance 0 in our accessibility model). However, once again, this accessibility is concentrated in the same location as the health centre, and does not extend to any great extent to the surrounding county, showing the capacity for concentrating accessibility possessed by the main focus of Madrid and the axis connecting it with Barcelona, which creates this gradient.

Figure 6.C shows the same picture for accessibility in the field of education, which is also organised on two levels of attraction, specialised (university) and essential (compulsory secondary education). The results follow the same pattern already shown above: polarisation on the Guadalajara-Madrid axis, with a gradient around the Madrid-Barcelona motorway and concentration on the locations with secondary schools. Once again, the location of these endowments determines the accessibility value for the municipalities. In this case, the tendency for these to be concentrated in the area around the motorway axis and in the south of the province creates a grouping with positive accessibility to the detriment of the areas to the north-west and north-east, which are configured as accessibility gaps on this educational component.

The last figure (6.D) shows the combined accessibility for all the three aspects analysed above, and groups the results into five categories. These show an area of better accessibility around the axis created by the Madrid-Barcelona motorway, as seen in the previous partial results. There is a certain gradient towards the west, towards the Henares Corridor, due to the attraction of the provincial capital and Madrid, and an extension of the positive values in central positions to the south, created by the concentration of educational resources and the relative proximity to the motorway compared to the rest of the provincial sample. The areas in the north-west, southwest and central space have negative accessibility values, but not the worst, mainly due to a factor of proximity to the above-mentioned areas, but they do have a lack of healthcare and, above all, educational facilities. The areas with the worst combined accessibility result are concentrated especially in small areas to the north and a striking grouping in the east of the province, which contrasts with some particular locations with positive accessibility in the same environment and without a gradient to intermediate situations. It is precisely this sudden change from very positive to very negative situations that stands out. It is notable that, although the distance function is gradually distributed, a qualified calculation of accessibility reflects the disparities in the location of facilities and infrastructure and the hierarchy of the road network.

\subsection{Demographics and accessibility}

Table 3 shows the results of applying Pearson's bivariate correlation methodology to the results described above. All the pairs of variables have statistical significance, demonstrating their independence. There is a greater correlation between the variables in each area of analysis, as expected: real annual growth rate and population density show a high positive correlation, reflecting the trend that the higher the population density the greater the tendency to have positive population growth. On the other hand, the accessibility variables also correlate with each other, especially the healthcare and education components with the total aggregate, showing that, in the accessibility model built here, the location of primary care and secondary education facilities have influenced combined accessibility more than the other factors, especially the connection to urban areas. This is probably also because the cities in the study area are more evenly distributed than the healthcare and educational facilities. 
Tab 3. Correlation between population variables and accessibility. Source: Own calculations using spatial data from CNIG and Spanish National Institute of Statistics (INE).

\begin{tabular}{|c|c|c|c|c|c|c|}
\hline & \begin{tabular}{|l|} 
Annual \\
Growth Rate
\end{tabular} & Density & $Z A c c_{i}^{U r b}$ & $Z A c c_{i}^{\text {Health }}$ & $Z A c c_{i}^{E d u}$ & $\boldsymbol{A T o t}_{\mathrm{i}}$ \\
\hline $\begin{array}{l}\text { Annual } \\
\text { Growth Rate }\end{array}$ & 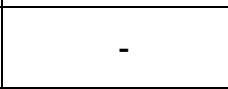 & $.629^{\star \star}$ & $.400^{* *}$ & $.342^{* *}$ & $.416^{* *}$ & $.394^{* *}$ \\
\hline Density & & - & $.606^{* *}$ & $.562^{* *}$ & $.691^{* * *}$ & $.633^{* *}$ \\
\hline$Z A c c_{i}^{U r b}$ & & & - & $.459^{* *}$ & $.556^{* *}$ & $.461^{* *}$ \\
\hline ZAcc ${ }_{i}^{\text {Health }}$ & & & & - & $.637^{* * *}$ & $.945^{* *}$ \\
\hline$Z A c c_{i}^{E d u}$ & & & & & - & $.719^{* *}$ \\
\hline ATot $_{i}$ & & & & & & - \\
\hline
\end{tabular}

${ }^{* *}$. Correlation is significant at the 0.01 level (bilateral).

In this instance, the most interesting aspect is the comparison between the two areas of analysis, since this is the focus of the working hypothesis. There is a significant and positive correlation in all cases between AGR and accessibility, both by component and in combination. Similarly, the same can be seen with population density, which shows a higher coefficient value than AGR; i.e., the higher the population density of the sample, the greater the accessibility. Demographic dynamics show this same interpretation, but quantitatively less pronounced than in the case of population density, by about two-tenths in all cases. For the accessibility components, access to the education sector shows higher coefficients than the rest, although very close to accessibility to urban areas. This demonstrates that the distribution of health centres balances the results better and correlates to a lesser extent with low results on growth and population density.

By combining the results, the sample can be classified in relation to its combined position in both areas: population dynamics and accessibility. For this purpose, Figure 7 was created, which shows a dispersion graph with the combined results for accessibility and AGR. It offers a synthetic, intuitive classification of four possible situations:

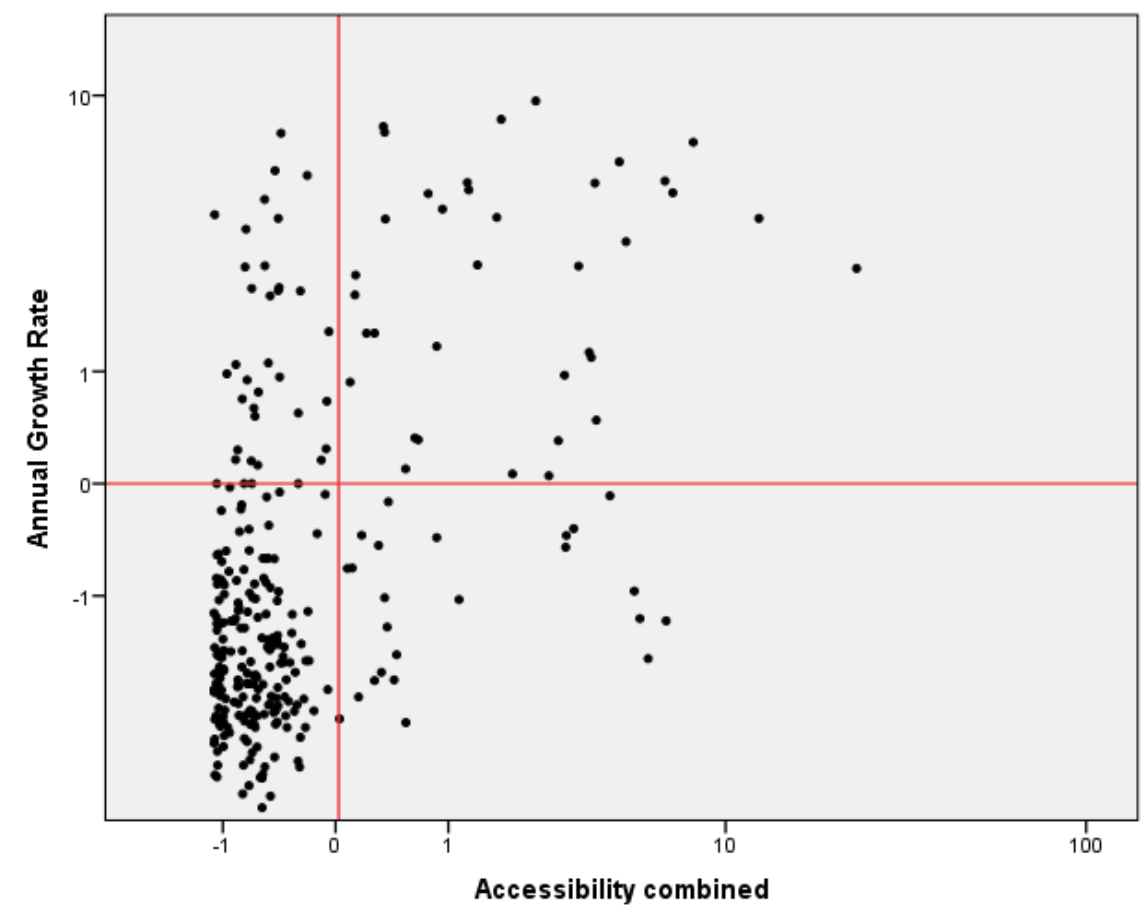




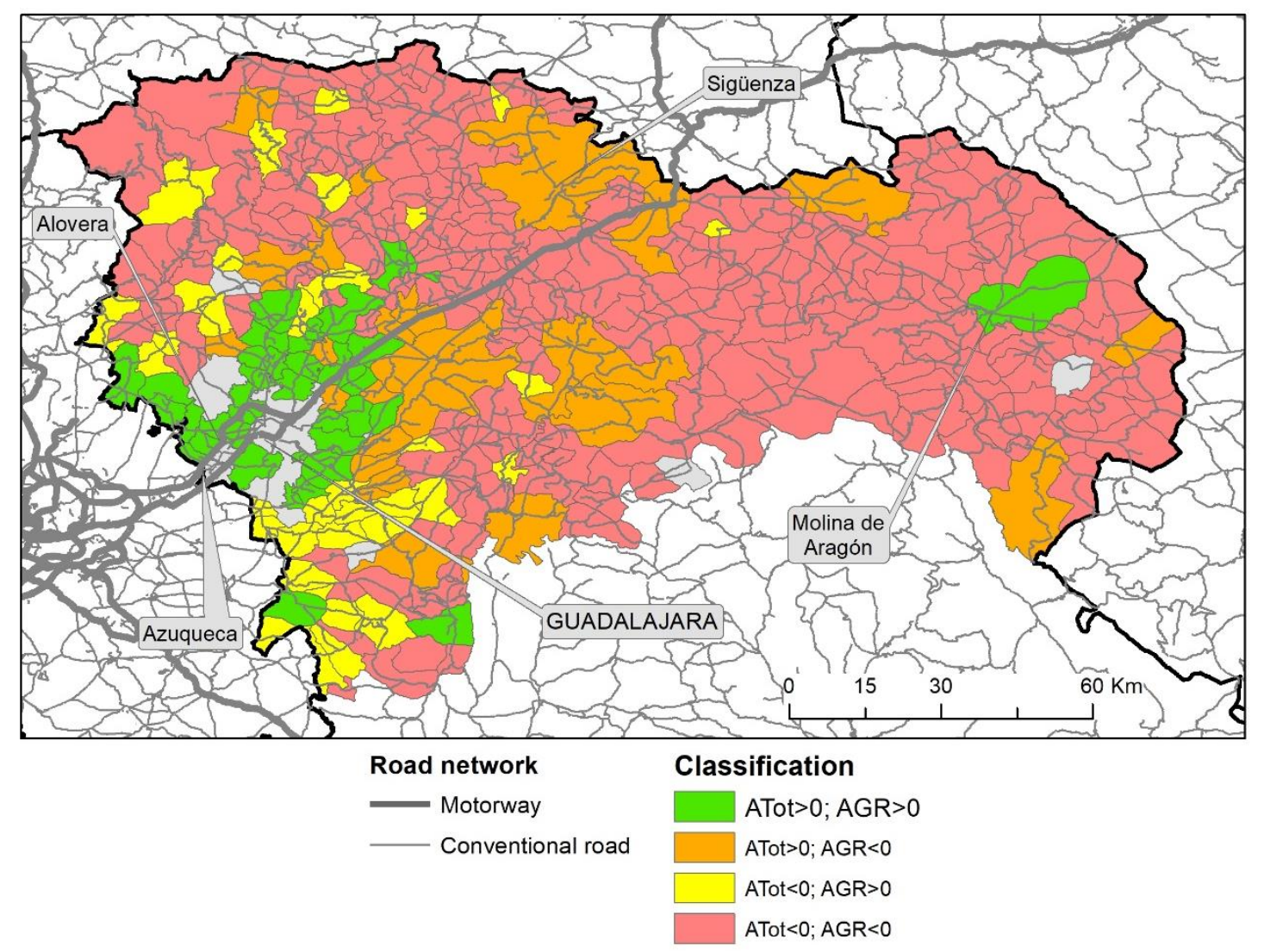

Fig 7. Accessibility and AGR combined. Source: CNIG, Spanish National Institute of Statistics (INE). Own elaboration

1) Municipalities with a positive value on both variables have optimal accessibility and population dynamics and are therefore dynamic. In the maps attached to this analysis, these municipalities are to be found in the immediate surroundings of Guadalajara and one case in the extreme east of the province (Sigüenza), which is a county capital and a local centre for goods and services.

2) Municipalities in the opposite situation, with negative results for combined accessibility and AGR. These are the most numerous (193 municipalities out of the total). They, therefore, show a negative structural situation, both from the demographic point of view and territorial cohesion perspective.

3) Municipalities in an intermediate situation, with one of the variables positive and the other negative. These two groups are few in numbers and point to intermediate situations in between the extremes described above.

a. Municipalities with good accessibility but negative population dynamics point to situations with good connectivity but little structural capacity to take advantage of the opportunity presented by their location.

b. On the other hand, municipalities with good population dynamics but a negative accessibility value are small nuclei that have certain connectivity disadvantages but some potential for retaining their population, usually because they have community facilities.

\section{Discussion}

The discussion should start with some comments on the limitations of the analytical model, which determine the strength of the results obtained. Decisions were made about which expressions to use, which variables to include, and the value of some parameters. Friction was implemented 
using a potential formula that enhances the loss of attraction as the time travel between points increases, emphasising the effect of distance. It should be remembered that these decisions affect the results and an option for future work would be to conduct sensitivity studies on these issues, which would make it possible to assess the impact of the methodology on the results themselves.

We have demonstrated how scale affects results and its interpretation. Accessibility, as many other spatial features is very sensitive to the scale of the analysis. Previous results show good accessibility results to our study case (Ballas, et al., 2003; Spiekermann and Wegener, 2003; van Eupen et al., 2012; Vickerman et al., 1999) due to the scale of the analysis and is considerably larger than in our study. In larger samples, proximity and distance overlap other criteria, such as demographic or economic elements and accessibility may be biased for this reason. This effect highlights peripheralization as a physical concept, while hiding the functional aspect of marginalization.

Turning to the discussion of these results, several interesting reflections can be made. The demographic analysis shows the reality of a province with predominantly rural features, which has been subjected to unbalanced growth in a very specific part of its territory. The development of industrial land by Madrid has been an external factor with logical demographic, social, economic and territorial consequences. A model dependent on Madrid and its communication routes that does not consider established administrative boundaries, but is spatially propagated, considering the advantages and gains derived from the communication routes. The rest of the territory that has not been exposed to this spatial expansion process has a demographic model with the most sparsely populated areas in Europe, so that the discussion that arises is how to promote the development of these sparsely populated areas and coordinate this with areas that are increasing in population. In short, it is a territorial debate that is very ambitious, given the long-standing limitations presented by these spaces. The results allow us to state that the economic development of sparsely populated areas must necessarily begin from the ability to access crucial services and facilities that contribute to the well-being and quality of life, leading to the consolidation of rural spaces.

In this regard, we consider that the debate on rural depopulation should not respond exclusively to population retention or improvement of certain demographic indicators, it should be based also on qualitative terms related to optimise access to the health system that contributes to balance social inequalities. Accessibility to educational and other functions (urban areas) would promote the social capital needed to enhance cohesion and territorial development through capacitation on formation, entrepreneurship, and consolidation of urban-rural connection. In short, achieving a better level of cohesion through greater integration of urban-rural relations, as recommended by the ESPON Observatory. The identification of municipalities that act as educational and health service centres should be the starting point for implementing equitable territorial development formulas, in which these centres provide essential services to their closest area of influence. It is a question of encouraging polycentric models that correct the problem raised by an unbalanced territorial model, as has been seen. Marginalization is related with distance, but not exclusively, functions also take a part and, according to Kühn (2015) peripheralization is a process linked with the lack of influence and dependence in the decision-making process.

The first policy measures aimed at reversing rural depopulation already bet on the strengthening of these services in Guadalajara province. For example, Integrated Territorial Investments (ITI), is an instrument established by the European Union to facilitate integral actions in territories that show depopulation, already proposes initiatives focused on the renovation of facilities, heading to the provision of small-scale basic health services. In addition, ITI bets on social welfare, from care of elderly people, to general access to education, culture, and new technologies. The results obtained could be taken into account when implementing such initiatives in the territory. The location of basic health services should be based on the accessibility problems of those municipalities located in the fourth quartile, where there is only one health centre. Additionally, there is a lack of educative facilities in the third and fourth accessibility quartiles, proving the need for an organization based on mobility and travel times to guarantee basic education. This problem could be solved through the gradual incorporation of other social and cultural facilities that allow the development of the knowledge society in these areas that are weakly populated. 
It has also been shown that demographic behaviour depends directly on the existing level of accessibility. Population increase implies the multiplication of basic services in the territory, especially those dedicated to education and healthcare. The authors consider that it is essential to take these services into account in any study of rural accessibility for several reasons: firstly, because they are two basic pillars of the welfare state; secondly, because their presence reflects the reality of the age structure, that is, the more educational institutions, the more young people, and the more health centres, the more care for the elderly, so considering them is an integral part of the package; and thirdly, these services determine a significant part of the population flows in rural areas, apart from those that are purely work-related, which become greatly diluted as the municipality becomes more rural.

On this point, it should be noted that this issue must be emphasised in the Spanish distribution of competences, in which the health and education systems have been transferred to the regions (the Autonomous Regions). As a result, the areas of influence for health centres and secondary schools are affected by the administrative boundaries of the regions and this artificially alters the distance gradient, introducing barriers to accessibility. This can be the subject of a more detailed analysis for those municipalities that may be at a disadvantage when the services nearby are run from the outside, emphasising their isolated situation. These situations should form part of a proactive territorial policy, as they represent obvious challenges for territorial cohesion from a structural point of view.

Taking health and educational centres into account has also shown that they lead to centralisation in the municipalities where these facilities are situated and not to dispersion into the surrounding area, as their areas of influence are limited by distance. There is a correlation between these locations and their population dynamics, but they act by concentrating the potential in their own location and their territorial surroundings do not cohere around them.

Consequently, analysing accessibility to urban centres and health and education, infrastructure can be considered an appropriate way to measure population flows, and the introduction of another reference for measuring accessibility did not substantially change the model obtained.

The closeness or proximity to service centres of rural municipalities with a low population density is no guarantee of accessibility or, therefore, of population growth either. It is the result of an exogenous territorial development model that does not consider the generation of imbalances or the possibility of mitigating them.

\section{Conclusions}

The decision-making process regarding industrial and service development has clear territorial consequences. In our case, a model of exogenous development around a transport route led to significant population growth which, in turn, gave rise to a whole series of service infrastructures. The places that were left out of this type of initiative have headed toward stagnation, seriously limiting their opportunities for territorial development, even when they were, a priori, relatively close to municipalities with very good accessibility.

Results also demonstrate that having short travel times does not guarantee spatial cohesion, because shorter distances does not assure effective integration, proving our hypothesis. Distance is not the determining factor in explaining territorial dynamics, which depend on other factors to generate momentum, whether positive or negative. The attraction of traditional centres of development and traditional metropolitan areas remains a key element, although proximity to them does not guarantee participation in their dynamics. On the contrary, in contexts like the one analysed, it emphasises the differences and exaggerates the opposite dynamics, the positive and the negative.

Nevertheless, smart territorial solutions must be proposed that do not depend on the actions or policies set by other regions. Each territory must propose comprehensive development strategies so as not to rely on these exogenous developments; instead, they must take advantage of internal synergies, to benefit from these infrastructures. 
This study leaves open options for examining this line of research in greater depth. Firstly, by testing the methodology and testing the variables used and introducing new ones that expand the explanatory base. One example could be ageing, which structurally affects populations and is characteristic of depopulated spaces. In the same way, accessibility could be analysed from a functional perspective, not only a synthetic one, making it possible to achieve a more effective characterisation of the territorial split in rural spaces, despite their being close to economically dynamic spaces.

\section{Acknowledgments}

This research is linked to the Project "Los Paisajes Culturales Agrarios en Castilla-La Mancha como base del desarrollo territorial" (CODE: SBPLY / 19/180501/000041) funded by Junta de Comunidades de Castilla-La Mancha (Spain) and ERDF (European Regional and Development Fund).

Academic references

[1] Adom-Asamoah, G., Amoako, C. \& Adarkwa, K. K. (2020). Gender disparities in rural accessibility and mobility in Ghana. Case Studies on Transport Policy, 8(1), 49-58. DOI: 10.1016/j.cstp.2019.12.006.

[2] Ahern, A. \& Hine, J. (2015). Accessibility of Health Services for Aged People in Rural Ireland. International Journal of Sustainable Transportation, 9(5), 389-395. DOI: 10.1080/15568318.2013.800926.

[3] Ballas, D., Kalogeresis, T. \& Labrianidis, L. (2003). A comparative study of typologies for rural areas in Europe. In 43rd Congress of the European Regional Science Association: Peripheries, Centres, and Spatial Development in the New Europe (pp. 1-38). Louvain-laNeuve: European Regional Science Association.

[4] Barnett, S., Roderick, P., Martin, D. \& Diamond, I. (2001). A multilevel analysis of the effects of rurality and social deprivation on premature limiting long term illness. Journal of Epidemiology and Community Health, 55(1), 44-51. DOI: 10.1136/jech.55.1.44.

[5] Bhat, C., Handy, S., Kockelman, K., Mahmassani, H., Chen, Q. \& Weston, L. (2000). Development of an Urban Accessibility Index: Literature [Technical report]. Austin: University of Texas.

[6] Bock, B. (2016). Rural Marginalisation and the Role of Social Innovation; A Turn Towards Nexogenous Development and Rural Reconnection. Sociologia Ruralis 56(4), 552-573. DOI: 10.1111/soru.12119.

[7] Brezzi, M., Dijkstra, L. \& Ruiz, V. (2011). OECD extended regional typology: the economic performance of remote rural regions [OECD Regional Development Working Papers]. Paris: OECD Publishing. DOI: 10.1787/5kg6z83tw7f4-en.

[8] Caschili, S., De Montis, A. \& Trogu, D. (2015). Accessibility and rurality indicators for regional development. Computers, Environment and Urban Systems, 49, 98-114. DOI: 10.1016/j.compenvurbsys.2014.05.005.

[9] Christiaanse, S. (2020). Rural facility decline: A longitudinal accessibility analysis questioning the focus of Dutch depopulation-policy. Applied Geography, 121, 102251. DOI: 10.1016/j.apgeog.2020.102251.

[10] Cloke, P. (2006). Conceptualizing rurality. In Cloke, P., Mardsen, T. \& Mooney, P., eds., Handbook of rural studies (Vol. 18). London: SAGE Publications Ltd.

[11] Collantes, F., Pinilla, V., Sáez, L. A. \& Silvestre, J. (2013). Reducing Depopulation in Rural Spain: The Impact of Immigration. Population, Space and Place, 20(7), 606-621. DOI: 10.1002/psp.1797. 
[12] Curtis, C. \& Scheurer, J. (2010). Planning for sustainable accessibility: Developing tools to aid discussion and decision-making. Progress in Planning, 74(2), 53-106. DOI: 10.1016/j.progress.2010.05.001.

[13] Delgado, C. (2019). Depopulation processes in European rural areas: a case study of Cantabria (Spain). European Countryside, 11(3), 341-369. DOI: 10.2478/euco-2019-0021.

[14] Díaz, M. A., Jiménez, F. J. \& Lorente, I. (2002). Estructura territorial y relaciones funcionales en el Corredor del Henares: una aproximación desde la movilidad diaria de la población. Anales de Geografía de la Universidad Complutense (22), 301-327.

[15] Del Río, I. \& Rodríguez, J. (2009). Áreas metropolitanas en transformación. Presente y futuro del Corredor del Henares en el área funcional madrileña. Anales de Geografía de la Universidad Complutense (29), 139-165.

[16] Dunaway, W. A. (1996). The incorporation of mountain ecosystems into the capitalist worldsystem. Review (Fernand Braudel Center) 19(4), 355-381.

[17] Farrington, J. \& Farrington, C. (2005). Rural accessibility, social inclusion and social justice: towards conceptualisation. Journal of Transport Geography, 13(1), 1-12. DOI: 10.1016/j.jtrangeo.2004.10.002.

[18] Gáková, Z. \& Dijkstra, L. (2010). Does population decline lead to economic decline in EU rural regions? Regional Focus 1/2010.

[19] Geurs, K. T. \& van Wee, B. (2004). Accessibility evaluation of land-use and transport strategies: Review and research directions. Journal of Transport Geography, 12(2), 127140. DOI: $10.1016 /$ j.jtrangeo.2003.10.005.

[20] Gutiérrez Puebla, J. (1991). Indicadores de accesibilidad en transporte público en el medio rural: una propuesta metodológica. Estudios Geográficos, 52(203), 205.

[21] Hansen, W. G. (1959). How Accessibility Shapes Land Use. Journal of the American Institute of Planners, 25(2), 73-76. DOI: 10.1080/01944365908978307.

[22] Heffner, K. \& Latocha, A. (2020). Desolated Villages as Examples of Spatial, Economic and Social Marginalization in the Polish-Czech Borderland and Their Current Transformations. In: Nel E. \& Pelc S., eds., Responses to Geographical Marginality and Marginalization. Perspectives on Geographical Marginality, vol 5 (pp. 123-142). Cham: Springer. DOI: 10.1007/978-3-030-51342-9_8.

[23] Holl, A. (2007). Twenty years of accessibility improvements. The case of the Spanish motorway building programme. Journal of Transport Geography, 15(4), 286-297. DOI: 10.1016/j.jtrangeo.2006.09.003.

[24] Isserman, A. M. (2005). In the national interest: Defining rural and urban correctly in research and public policy. International Regional Science Review, 28(4), 465-499. DOI: $10.1177 / 0160017605279000$.

[25] Kanuganti, S., Sarkar, A. K., Singh, A. P. \& Arkatkar, S. S. (2015). Quantification of accessibility to health facilities in rural areas. Case Studies on Transport Policy, 3(3), 311320. DOI: 10.1016/j.cstp.2014.08.004.

[26] Kühn, M. (2015). Peripheralization: Theoretical Concepts Explaining Socio-Spatial Inequalities. European Planning Studies, 23(2), 367-378. DOI: $10.1080 / 09654313.2013 .862518$.

[27] Labianca, M. \& Navarro, F. (2019). Depopulation and aging in rural areas in the European Union: practices starting from the LEADER approach. Perspectives on rural development, 3 , 223-252. DOI: 10.1285/i26113375n3p223.

[28] Lenormand, M., Bassolas, A. \& Ramasco, J. J. (2016). Systematic comparison of trip distribution laws and models. Journal of Transport Geography, 51, 158-169. DOI: $10.1016 /$ j.jtrangeo.2015.12.008. 
[29] Levine, J. (2020). A century of evolution of the accessibility concept. Transportation Research Part D: Transport and Environment, 83, 102309. DOI: 10.1016/j.trd.2020.102309.

[30] López-i-Gelats, F., Tàbara, J. D. \& Bartolomé, J. (2009). The rural in dispute: Discourses of rurality in the Pyrenees. Geoforum, 40(4), 602-612. DOI: 10.1016/j.geoforum.2009.04.008.

[31] Martínez, H., Mohíno, I., Ureña, J. \& Solís, E. (2014). Road accessibility and articulation of metropolitan spatial structures: the case of Madrid (Spain). Journal of Transport Geography, 37, 61-73. DOI: 10.1016/j.jtrangeo.2014.04.003.

[32] Martínez Sánchez-Mateos, H. (2018). Defining rural: a functional and accessibility approach applied in Castilla-La Mancha (Spain). Redes, 23(3), 248-266. DOI: $10.17058 /$ redes.v23i3.12245.

[33] Mohíno, I., Ureña, JM. \& Martínez, HS. (2014). Relaciones funcionales de profesionales altamente cualificados en áreas distantes de regiones urbanas multicéntricas: el caso de los Ingenieros de Caminos en el contexto madrileño, Scripta Nova, 18(488).

[34] Molinero, F. (2019). El espacio rural de España: evolución, delimitación y clasificación. Cuadernos Geográficos 58(3), 19-56. DOI: 10.30827/cuadgeo.v58i3.8643.

[35] Morrissey, K., Clarke, G., Ballas, D., Hynes, S. \& O'Donoghue, C. (2008). Examining access to GP services in rural Ireland using microsimulation analysis. Area, 40(3), 354-364. DOI: 10.1111/j.1475-4762.2008.00844.x.

[36] Moseley, M. J. (1979). Accessibility: the rural challenge. London: Metheuen.

[37] Mu, L., Chen, Y. \& Zhen, C. (2020). SNAP office accessibility and its association with rurality. Applied Geography, 120. DOI: 10.1016/j.apgeog.2020.102209.

[38] Murawski, L. \& Church, R. L. (2009). Improving accessibility to rural health services: The maximal covering network improvement problem. Socio-Economic Planning Sciences, 43(2), 102-110. DOI: 10.1016/j.seps.2008.02.012.

[39] Neumeier, S. (2016). Accessibility to Services in Rural Areas: The Example of Petrol Service Provision in Germany. DISP, 52(3), 32-49. DOI: 10.1080/02513625.2016.1235877.

[40] Peacock, A. \& Pemberton, S. (2019). The paradox of mobility for older people in the ruralurban fringe. Journal of Rural Studies, 70, 9-18. DOI: 10.1016/j.jrurstud.2019.08.002.

[41] Pinilla, V., Ayuda, M. A. \& Sáez, L. A (2008). Rural depopulation and the migration turnaround in mediterranean Western Europe: A case study of Aragon. Journal of Rural and Community Development, 3,1-22.

[42] Ranković Plazinić, B. \& Jović, J. (2018). Mobility and transport potential of elderly in differently accessible rural areas. Journal of Transport Geography, 68, 169-180. DOI: 10.1016/j.jtrangeo.2018.03.016.

[43] Reggiani, A., Bucci, P., Russo, G., Haas, A. \& Nijkamp, P. (2011). Regional labour markets and job accessibility in City Network systems in Germany. Journal of Transport Geography, 19(4), 528-536. DOI: 10.1016/j.jtrangeo.2010.05.008.

[44] Reynaud, C. \& Miccoli, S. (2018). Depopulation and the Aging Population: The Relationship in Italian Municipalities. Sustainability, 10, 1004. DOI: 10.3390/su10041004.

[45] Rogerson, P. (2006). Statistical methods for Geography. London: SAGE.

[46] Ruiz, A. R. \& Cañizares, M. C. (2020). Enhancing the Territorial Heritage of Declining Rural Areas in Spain: Towards Integrating Top-Down and Bottom-Up Approaches. Land, 9, 216. DOI: $10.3390 /$ land9070216.

[47] Salze, P., Banos, A., Oppert, JM., Charreire, H., Casey, R., Simon, Ch., Chaix, B., Badariotti, D. \& Weber, Ch. (2011). Estimating spatial accessibility to facilities on the regional scale: an extended commuting-based interaction potential model. International Journal of Health Geographics, 10(2). DOI: 10.1186/1476-072X-10-2. 
[48] Schatz, L. (2017). Going for growth and managing decline: the complex mix of planning strategies in Broken Hill, NSW, Australia. Town Planning Review 88(1), 43-57. DOI: 10.3828/tpr.2017.5.

[49] Shah, T. I., Milosavljevic, S. \& Bath, B. (2017). Measuring geographical accessibility to rural and remote health care services: Challenges and considerations. Spatial and SpatioTemporal Epidemiology, 21, 87-96. DOI: 10.1016/j.sste.2017.04.002.

[50] Syssner, J. \& Siebert, C. (2020). Local governments and the communication of demographic decline in Sweden and Germany: who, what and why? AGER 29, 79-105. DOI: 10.4422/ager.2020.01.

[51] Smith, N., Hirsch, D. \& Davis, A. (2012). Accessibility and capability: The minimum transport needs and costs of rural households. Journal of Transport Geography, 21, 93-101. DOI: 10.1016/j.jtrangeo.2012.01.004.

[52] Spiekermann, K. \& Wegener, M. (2003). Trans-European networks and unequal accessibility in Europe. In 43rd Congress of the European Regional Science Association: Peripheries, Centres, and Spatial Development in the New Europe, Vol. 4 (pp. 35-42). Louvain-la-Neuve: European Regional Science Association.

[53] Terluin, I. J. (2003). Differences in economic development in rural regions of advanced countries: an overview and critical analysis of theories. Journal of Rural Studies, 19(3), 327344. DOI: 10.1016/S0743-0167(02)00071-2.

[54] van Eupen, M., Metzger, M. J., Pérez-Soba, M., Verburg, P. H., van Doorn, A. \& Bunce, R. G. H. (2012). A rural typology for strategic European policies. Land Use Policy, 29(3), 473482. DOI: 10.1016/j.landusepol.2011.07.007.

[55] Vickerman, R. (1995). Location, accessibility and regional development: the appraisal of trans-European networks. Transport Policy, 2(4), 225-234. DOI: 10.1016/S0967070X(95)00013-G.

[56] Vickerman, R., Spiekermann, K. \& Wegener, M. (1999). Accessibility and Economic Development in Europe. Regional Studies, 33(1), 1-15. DOI: 10.1080/00343409950118878.

[57] Vitale Brovarone, E. \& Cotella, G. (2020). Improving rural accessibility: A multilayer approach. Sustainability, 12(7). DOI: 10.3390/su12072876.

[58] Wiggins, S. \& Proctor, S. (2001). How Special are Rural Areas? the Economic Implications of Location for Rural Development. Development Policy Review, 19(4), 427-436. DOI: $10.1111 / 1467-7679.00142$.

[59] Woods, M. (2016). International migration, agency and regional development in rural Europe. Documents D'Anàlisi Geogràfica, 62(3), 569-593. DOI: 10.5565/rev/dag.372.

[60] Yeager, C. D. \& Gatrell, J. D. (2014). Rural food accessibility: An analysis of travel impedance and the risk of potential grocery closures. Applied Geography, 53, 1-10. DOI: 10.1016/j.apgeog.2014.05.018.

\section{Other sources}

[61] European Union (2011). Territorial Agenda of the European Union 2020. Towards an Inclusive, Smart and Sustainable Europe of Diverse Regions. Gödölló, (Hungary).

[62] European Union (2013). How can regional and cohesion policies tackle demographic challenges? Directorate General for internal policies. https://op.europa.eu/en/publicationdetail/-/publication/68dcf076-c1b4-4bfa-8515-f04e65a5ecf2.

[63] European Union (2016). Sparsely populated and underpopulated areas. EPRS. https://www.europarl.europa.eu/RegData/etudes/BRIE/2016/586632/EPRS_BRI(2016)586 632_EN.pdf. 
[64] European Union (2019). Demographic trends in EU regions. European Parliamentary Research Service. https://ec.europa.eu/futurium/en/system/files/ged/eprs-briefing-633160demographic-trends-eu-regions-final.pdf.

[65] ESPON (2011). European development opportunities for rural areas (EDORA). Applied Research 2013/1/2. Final Report, Luxembourg: ESPON.

[66] Nordregio (2012). Making the best of Europe's sparcely populated areas. On making geographic specificity a driver for territorial development in Europe. Nordregio Working Paper, 15, 1-84.

[67] OECD (Organisation for Economic Co-operation and Development). (1994). Creating rural indicators for shaping territorial policy. París: OECD. 